\title{
Condições de deformação, metamorfismo e fusão parcial do Complexo Porto Belo a sul da Zona de Cisalhamento Major Gercino, Bombinhas (SC)
}

\author{
Franciele G. ANDRES \& Maria de Fátima BITENCOURT \\ Programa de Pós-Graduação em Geociências, Universidade Federal do Rio Grande do Sul, Av. Bento \\ Gonçalves, 9500,91501-970, Porto Alegre, Brasil (franciele.andres@ufrgs.br, fatimab@ufrgs.br).
}

\begin{abstract}
Resumo. Regimes transpressivos, típicos de colisões oblíquas, são caracterizados por uma tectônica de baixo ângulo que precede e se superpõe à tectônica de alto ângulo nas fases iniciais da colisão. Na porção centro-leste do Escudo Catarinense, o Complexo Porto Belo (CPB) constitui o embasamento da Zona de Cisalhamento Major Gercino, de cinemática transcorrente destral e direção NE-SW, que controla a ascensão e posicionamento de magmas graníticos no estágio pós-colisional do Ciclo Brasiliano. A área estudada está situada a sul desta zona, onde o CPB preserva estruturas relacionadas à tectônica de baixo ângulo. Uma abordagem integrada de geologia estrutural e petrografia foi utilizada a fim de estabelecer as condições de deformação e metamorfismo nas rochas do complexo. O estudo identificou uma associação de gnaisses tonalíticos a dioríticos, granodioritos e anfibolitos, com ocorrência subordinada de migmatitos. Os anfibolitos são finamente laminados e formam camadas boudinadas. Os ortognaisses têm bandamento $\left(\mathrm{S}_{\mathrm{b}}\right)$ milimétrico, de direção NE-SW com baixo ângulo de mergulho para SE. Os granodioritos são porfiríticos, com foliação magmática $\left(\mathrm{S}_{0}\right)$ de direção $\mathrm{N}$-S e mergulho de médio ângulo para leste. Essas litologias são afetadas por dobras isoclinais recumbentes e horizontais inclinadas, com vergência para SW. Indicadores cinemáticos como xenólitos deformados e porfiroclastos assimétricos demonstram transporte tectônico de topo para NW. Feições migmatíticas são encontradas em todas as litologias, mas geram apenas pequenos volumes de leucossoma in situ e in source. As condições de metamorfismo e deformação sugerem temperaturas compatíveis com as da fácies anfibolito médio a superior para a geração dos ortognaisses e cristalização sintectônica do granodioritos.
\end{abstract}

Palavras-chave. Ciclo Brasiliano/Panafricano, Escudo Catarinense, fácies anfibolito, fusão parcial, migmatitos.

\begin{abstract}
Deformation, metamorphism and partial MELTING CONDITIONS OF the PORTO Belo COMPLEX SOUTH OF THE MAJOR GERCINO SHEAR ZONE, BOMBINHAS (SC). Transpressional settings, typical of oblique collisions, result in strain partitioning, initially characterized by thrust tectonics that progrades to and coexists with strike-slip tectonics. In the central-eastern portion of the Catarinense Shield, the Porto Belo Complex (PBC) comprises the basement of the dextral strike-slip, NE-trending Major Gercino Shear Zone (MGSZ). This shear zone has controlled the emplacement of successive magma pulses in the post-collisional stage of the Brasiliano Orogenic Cycle. The study area is located south of MGSZ, where the PBC records structures related to thrust tectonics. An integrated approach of structural geology and petrography was used in order to constrain the conditions of deformation and metamorphism in the rocks of the complex. In the study area, the PBC comprises orthogneisses, granodiorites, and amphibolites, with subordinate migmatites. The orthogneisses show mm-thick, NE-striking gneissic banding (Sb) which dips at shallow angles towards SE. The granodiorites are porphyritic and show NS-striking magmatic foliation that dips at moderate angles towards $E$. The amphibolites are finely-laminated and form boudinaged layers. These rocks are affected by isoclinal, recumbent and horizontal inclined folds, with top-to-the SW vergence. However, kinematic indicators as deformed xenoliths and asymmetric porphyroclasts show top-to-the-NW tectonic transport. Partial melting features are found in all rock types, but produce only small volumes of in situ and in source leucosome. Microstructures and mineral paragenesis suggest temperature conditions of mid- to upper amphibolite facies for the generation of the orthogneisses and crystallization of syntectonic granodiorites.
\end{abstract}

Keywords. Brasiliano Cycle, Catarinense Shield, amphibolite facies, partial melting, migmatite. 


\section{Introdução}

O registro estrutural das rochas précambrianas reflete importantes estágios da evolução crustal durante os ciclos orogênicos. Em colisões oblíquas, onde se desenvolvem regimes transpressivos, a deformação é particionada em duas componentes com movimentações distintas, uma de baixo ângulo e uma de alto ângulo (Van der Pluijm \& Marshak, 2004). Desta forma, a tectônica de baixo ângulo corresponde a um dos principais marcadores do estágio colisional, visto que compõe a fase inicial dos movimentos de empurrão associados à colisão continental e ao espessamento crustal.

Na porção sul da Província Mantiqueira, o Ciclo Brasiliano/Panafricano é caracterizado por arcos magmáticos pré-colisionais (e.g. Leite et al., 2000; Masquelin et al., 2012; Lenz et al., 2013; Martil et al., 2017), associados à subducção de crosta oceânica, com metamorfismo de alto grau desenvolvido durante a colisão principal, ca. $650 \mathrm{Ma}$ (Lenz et al., 2011; Chemale Jr. et al., 2012; Martil, 2016; De Toni et al., 2020a, 2020b). O estágio pós-colisional (ca. 650 - 580 Ma) é marcado por intenso magmatismo granítico, controlado por extensas zonas de cisalhamento, que integram o Cinturão de Cisalhamento Sulbrasileiro (Bitencourt \& Nardi, 1993, 2000). As rochas geradas durante este ciclo orogênico compõem o Cinturão Dom Feliciano (CDF), que se estende desde o sul do Uruguai até o estado de Santa Catarina, no sul do Brasil (Fig. 1A).

No Escudo Catarinense (EC), porção norte do CDF, o registro de uma tectônica tangencial de baixo ângulo é observado em rochas gnáissicas que compõem o embasamento dos granitoides pós-colisionais (Fig. 1B). Na região de Porto Belo-Bombinhas (SC), as rochas encaixantes desses granitoides compõem o Complexo Porto Belo (Florisbal et al., 2012a), cuja maior exposição está contida nos limites da Zona de Cisalhamento Major Gercino (ZCMG - Fig.1B), uma zona transcorrente de orientação NE-SW e cinemática destral, que oblitera e transpõe as principais características estruturais e geométricas preexistentes do complexo.

O Complexo Porto Belo (CPB) é composto por uma associação de ortognaisses de composição tonalítica e granodiorítica, biotita gnaisses e anfibolitos em menor expressão, além de granodioritos a monzogranitos porfiríticos. Sua evolução compreende um episódio metamórfico com geração de bandamento gnáissico, atribuído à tectônica tangencial do Ciclo Brasiliano (Bitencourt \& Nardi, 1993; Florisbal et al., 2012a). Uma vez que as estruturas resultantes do episódio de transcorrência se superpõem, e em grande parte obliteram a história precoce destas rochas, o estudo do complexo fora dos limites da ZCMG é importante para a compreensão de sua evolução tectônica.

Este trabalho tem por objetivo caracterizar a estrutura dos gnaisses e granitoides do Complexo Porto Belo fora dos limites da ZCMG, onde se encontram preservadas estruturas correlatas à tectônica tangencial de baixo ângulo, e de estabelecer as condições de metamorfismo e deformação associadas a este contexto.

\section{2 Área, materiais e métodos}

\subsection{Contexto geológico do Escudo Catarinense}

O Escudo Catarinense, localizado na porção norte do Cinturão Dom Feliciano, é dividido em três domínios tectônicos: Norte, Central e Sul. Estes domínios são delimitados pela Zona de Cisalhamento Itajaí-Perimbó (ZCIP), e pela Zona de Cisalhamento Major Gercino (Fig. 1B).

O Domínio Norte, limitado a sul pela ZCIP, abrange os ortognaisses e associações máficoultramáficas paleoproterozoicas do Complexo Granulítico de Santa Catarina (Hartmann et al., 1979) que, segundo Hartmann et al. (2000), tem idade de cristalização dos protólitos em 2716 $\pm 17 \mathrm{Ma}$, determinada por U-Pb SHRIMP em zircão. O complexo é recoberto por sequências sedimentares e vulcanossedimentares neoproterozoicas das bacias de Itajaí (Guadagnin et al., 2010) e Campo Alegre (Citroni et al., 2001).

O Domínio Central está localizado entre as zonas de cisalhamento Itajaí-Perimbó e Major Gercino. As unidades litoestratigráficas desta porção compreendem o Complexo Camboriú (CC), o Complexo Metamórfico Brusque (CMB) e intrusões graníticas (Fig. 1B).

O Complexo Camboriú (Chemale Jr. 


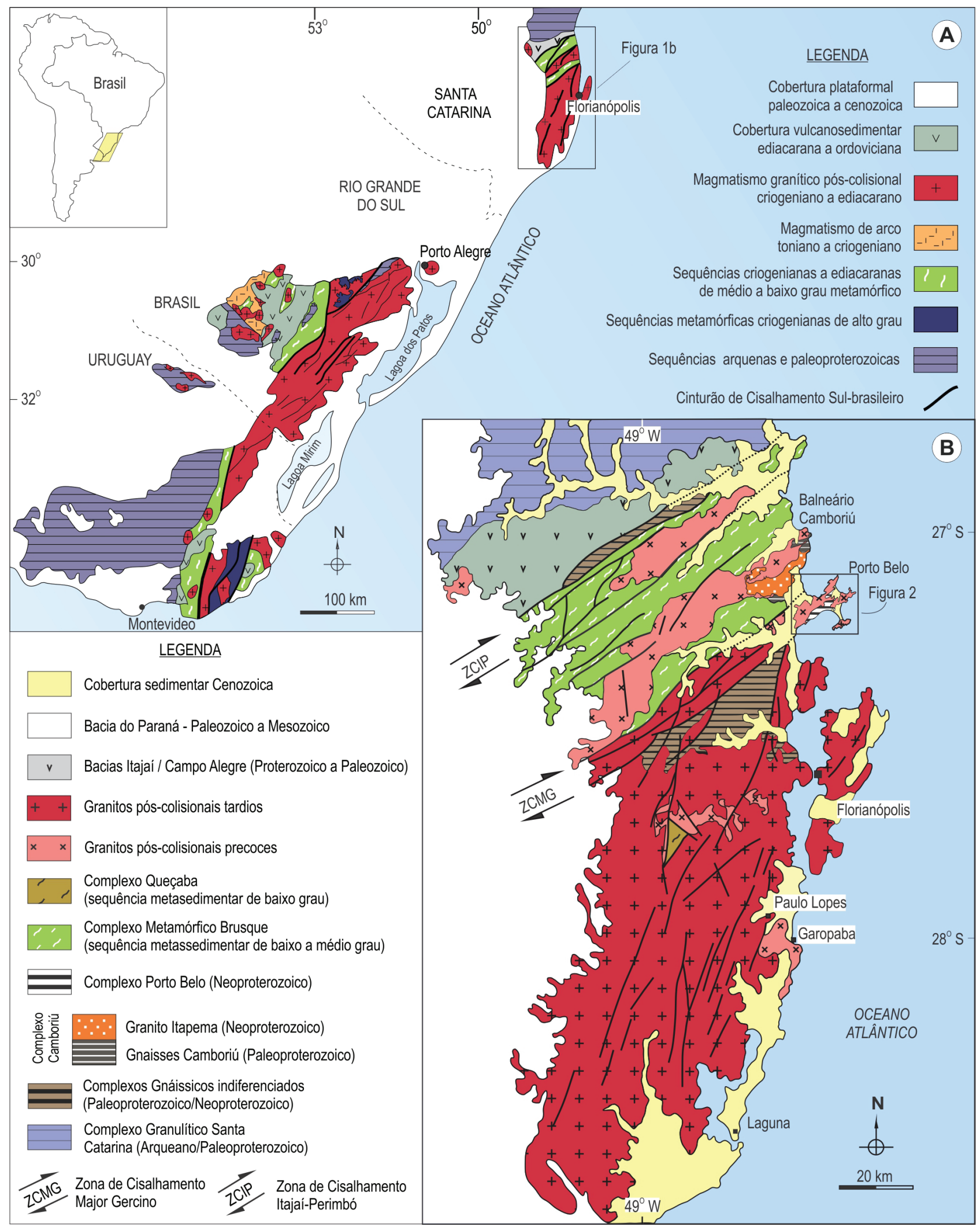

Figura 1. Contexto geológico regional. A) Compartimentação tectônica do segmento sul da Província Mantiqueira. Mapa geológico do Cinturão Dom Feliciano e áreas cratônicas adjacentes; B) Mapa geológico do Escudo Catarinense com a região de Porto Belo indicada (extraídas de Bitencourt, 1996 e modificadas de Florisbal et al., 2012a).

Figure 1. Geological setting. A) Major tectonic domains of Southern Mantiqueira Province. Geological map of Dom Feliciano Belt and adjacent cratonic areas; B) Geological map of the Catarinense Shield, with indication of the Porto Belo region (extracted from Bitencourt, 1996 and modified from Florisbal et al., 2012a). 
et al., 1995), embasamento deste domínio, é composto por rochas gnáissico-migmatíticas de composição tonalítica a granodiorítica, anfibolitos, e pelo Granito Itapema (Bitencourt \& Nardi, 2004). Os protólitos das rochas metamórficas têm idade de ca. 2,1 Ga, obtida por U-Pb SHRIMP em zircão (Hartmann et al., 2003; Silva et al., 2005), enquanto a idade da migmatização, ainda controversa, é datada entre 640 e 610 Ma por Basei et al. (2013). O Granito Itapema é composto por granodioritos a monzogranitos de textura heterogranular, cuja principal característica é a presença expressiva de xenólitos das encaixantes. Para alguns autores (e.g. Bitencourt \& Nardi, 2004; Martini et al., 2019a), o Granito Itapema foi gerado a partir da fusão parcial de gnaisses e anfibolitos do CC.

o Complexo Metamórfico Brusque corresponde a sequências metavulcânicas e metassedimentares de fácies xisto verde a anfibolito inferior (Silva, 1991; Philipp et al., 2004; Campos \& Philipp, 2007). Granitoides neoproterozoicos pós-colisionais intrudem as sequências metamórficas do CMB e seu embasamento (Philipp et al., 2004) (Fig. 1B).

O Domínio Sul engloba as rochas situadas no interior da Zona de Cisalhamento Major Gercino e a sul da mesma (Fig. 1B). A principal unidade geotectônica deste domínio é o Batólito Florianópolis, composto por granitoides neoproterozoicos interpretados por diversos autores (e.g. Bitencourt \& Nardi, 1993, 2000; Florisbal et al., 2012a, 2012b) como parte do magmatismo pós-colisional neoproterozoico. O embasamento deste domínio é formado por rochas paleoproterozoicas do Complexo Águas Mornas e rochas neoproterozoicas do Complexo Porto Belo (Chemale Jr. et al., 2012; De Toni et al., 2020a).

\subsection{Geologia da região de Porto Belo - Bombinhas}

A região de Porto Belo-Bombinhas (SC) encontra-se no extremo nordeste da Zona de Cisalhamento Major Gercino, com exceção do extremo sudeste da península, onde está localizada a área de estudos deste trabalho (Fig. 2). De acordo com Bitencourt (1996), esta zona de cisalhamento controlou o posicionamento de sucessivas intrusões graníticas que foram definidas como Granitoides de Quatro Ilhas (GQI), Granito Mariscal (GM), Complexo Granítico Estaleiro (CGE) e Suíte Intrusiva Zimbros (SIZ).

O embasamento dos granitoides sintectônicos corresponde a ortognaisses que eram descritos inicialmente como Complexo Camboriú (Silva, 1991; Chemale Jr. et al., 1995; Bitencourt, 1996; Silva et al., 2000) devido à escassez de estudos com enfoque específico nestas rochas. Noentanto, dados geocronológicos U-Pb LA-MC-ICMS em zircão apontaram idade de cristalização do protólito em $646 \pm$ 9,7 Ma (Chemale Jr. et al., 2012), não compatível com a idade paleproterozoica atribuída ao CC. Desta forma, Florisbal et al. (2012a) propuseram a designação de Complexo Porto Belo para os ortognaisses do embasamento da ZCMG. Recentemente, dados geocronológicos de U-Pb LA-ICP-MS em zircão, obtidos por De Toni et al. (2020a), demonstram idade de cristalização ígnea do protólito em $798 \pm 3,9 \mathrm{Ma}$.

O CPB predomina na porção sudoeste da península, com ocorrências descontínuas na porção nordeste e uma ocorrência isolada no extremo sudeste, interpretada por Bitencourt (1996) como roof pendant no Granito Morro dos Macacos (Fig. 2). A principal estruturação do CPB ocorreu durante a tectônica de baixo ângulo, responsável pela deformação e metamorfismo em condições mínimas de fácies anfibolito (Silva, 1991; De Toni et al., 2020a, 2020b), que gerou um bandamento sub-horizontal. Este bandamento é afetado por dobras isoclinais recumbentes $\mathrm{e}$ dobras tardias associadas ao mesmo evento e à transcorrência, que obliteram a geometria original do complexo (Bitencourt, 1996).

Os Granitoides de Quatro Ilhas e o Granito Mariscal representam a fase inicial do magmatismo sintectônico na ZCMG, são intrusivos nos ortognaisses do CPB e registram a tectônica tangencial e sua progressão para a tectônica transcorrente.

Os GQI compreendem biotita monzogranitos, leucossienogranitos e muscovita-biotita granodioritos a monzogranito de textura porfirítica, com fenocristais de K-feldspato. A foliação principal tem direção $\mathrm{NE}$, com mergulhos variáveis de baixo ângulo a 


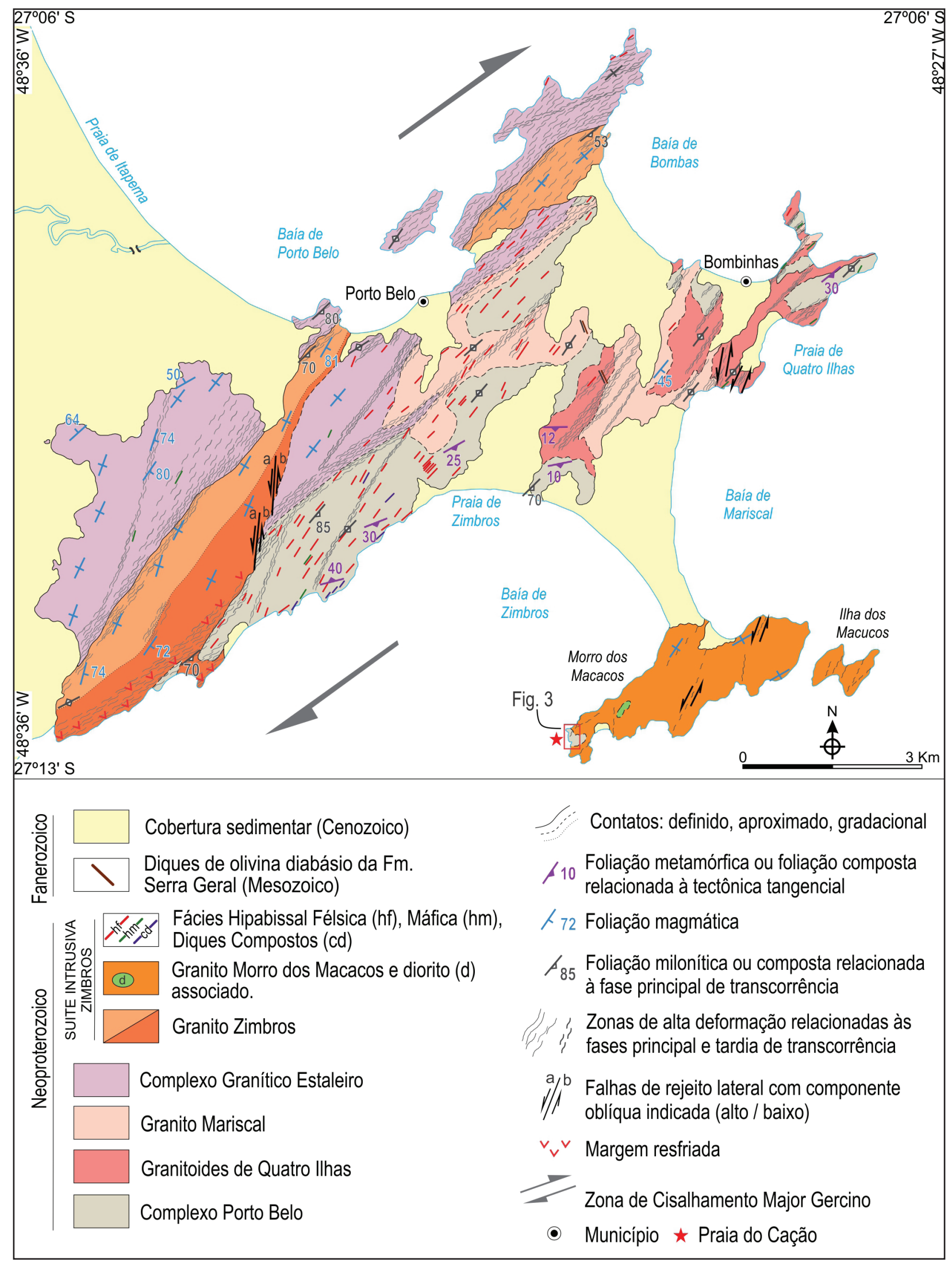

Figura 2. Mapa geológico da região de Porto Belo-Bombinhas (SC), com a área de estudo indicada (extraído e modificado de Bitencourt, 1996).

Figure 2. Geological map of Porto Belo-Bombinhas (SC) region, with indication of the study area (extracted and modified from Bitencourt, 1996). 
subverticais para SE, marcada pelo alinhamento de biotita que contorna os megacristais de K-feldspato e plagioclásio. Segundo Bitencourt (1996) e Bitencourt \& Kruhl, (2000), a foliação é magmática e resulta da progressão da deformação, inicialmente, em baixo ângulo progredindo para alto ângulo, associada à transcorrência. No contato com o embasamento, a foliação é sub-horizontal e xenólitos do CPB são comuns. A geocronologia U-Pb LA-ICP-MS em zircão aponta idades de cristalização de 625 \pm 7 Ma para o muscovita-biotita granodiorito, e $614 \pm 4$ Ma para o biotita monzogranito (Florisbal et al., 2012b).

O Granito Mariscal corresponde a muscovita-biotita siegnogranito de textura heterogranular, localmente porfirítica. Sua foliação magmática é descontínua, definida pelo alinhamento de micas e feldspatos e realçada por schlieren (Bitencourt, 1996). Xenólitos das rochas encaixantes são abundantes, tanto dos gnaisses do CPB como do GQI. Os dados geocronológicos U-Pb LA-MC-ICP-MS em zircão indicam idade de cristalização em $604 \pm 8$ Ma (Florisbal et al., 2012b) e $624 \pm 31$ Ma (Chemale Jr. et al., 2012). Os valores referidos, bem como a larga margem de erro do segundo, implicam uma idade pouco assertiva para esta unidade.

As idades obtidas por Florisbal et al. (2012b) indicam que o magmatismo precoce, que registra a tectônica tangencial, ocorreu entre 630 e $610 \mathrm{Ma}$. Os mesmos autores apontam que o magmatismo precoce tem contribuição de fontes mantélicas e crustais, enquanto o magmatismo associado à transcorrência tem fonte dominantemente crustal.

o Complexo Granítico Estaleiro predomina nas porções noroeste e sudoeste da região de Porto Belo (Fig. 2). Compreende o Granodiorito Estaleiro (GE), expressivos veios graníticos e, subordinadamente, corpos máficos tabulares (Bitencourt, 1996). Afoliação principalésubvertical com direção NE. Dados geocronológicos IDTIMS para o GE indeformado apontam idade de cristalização em $602 \pm 3 \mathrm{Ma}$ (Chemale Jr. et al., 2012). No entanto, dados geocronológicos mais recentes de U-Pb por LA-MC-ICP-MS em zircão demonstram idades de cristalização em $611 \pm$ 2,7 Ma, para o GE deformado, e $611 \pm$ 1,7 Ma para a porção indeformada (Peruchi, 2019).

A Suíte Intrusiva Zimbros é constituída pelo Granito Zimbros (GZ), Granito Morro dos Macacos (GMM), e por rochas hipabissais, concentradas a sudeste do Granito Zimbros (Fig. 2), denominadas de Fácies Hipoabissal Félsica, Fácies Hipoabissal Máfica e Diques Compostos. O GZ corresponde a um corpo alongado segundo a direção NE-SW (Fig. 2). Sua composição varia de biotita sienogranito a monzogranito, tem textura heterogranular a porfirítica e localmente é milonítico. Dados geocronológicos U-Pb LA-MCICP-MS em zircão demonstram idade de $587 \pm 8$ Ma (Chemale Jr. et al., 2012).

O GMM corresponde a biotita sienogranitos a monzogranitos de textura equigranular a heterogranular. Ocorre no extremo sudeste da península de Porto Belo e não mostra relações de contato com os outros corpos graníticos da região (Fig. 2). Localmente apresenta enclaves microgranulares máficos e dioritos associados (Bitencourt, 1996). Possui idade de cristalização U-Pb TIMS-ID em zircão de $588 \pm 3$ Ma (Chemale Jr. et al., 2012), e se encontra fora dos limites da Zona de Cisalhamento Major Gercino.

A área de estudo está localizada no extremo sudeste de Bombinhas, na região sudoeste do Morro dos Macacos (Fig. 2). Nessa região, as rochas do Complexo Porto Belo ocorrem em uma faixa costeira estreita, com aproximadamente $250 \mathrm{~m}$ de comprimento.

\subsection{Materiais e métodos}

Foram realizadas duas etapas de campo, com os objetivos de reconhecimento, caracterização geológico-estrutural, detalhamento estrutural e amostragem para confecção de lâminas petrográficas sob rigoroso controle estrutural. Esse controle refere-se à coleta de amostras orientadas em campo e lâminas confeccionadas a partir de corte perpendiculares à foliação e paralelos à lineação, para analisar possíveis indicadores cinemáticos no plano XZ.

Em laboratório, além do tratamento dos dados adquiridos em campo, foram realizadas análises petrográficas e microestruturais. Para o estudo de microestruturas foram confeccionadas 
15 lâminas delgadas, seguindo o padrão mencionado acima, a partir de 10 amostras, no Laboratório de Preparação de Amostras do Instituto de Geociências da UFRGS.

A caracterização geológico-estrutural envolveu a identificação, classificação e descrição das variações litológicas e das relações estratigráficas e estruturais entre elas. $\mathrm{O}$ detalhamento estrutural desenvolveu-se com a documentação das principais estruturas em meso- e macroescala, com a coleta sistemática de medidas estruturais e confecção de croquis de estruturas de interesse. A análise petrográfica e microestrutural consistiu na descrição das 15 lâminas delgadas em microscópio óptico Leica ${ }^{\circledR}$, modelo DM750 P, com classificação modal realizada a partir de estimativas visuais e nomenclatura baseada nos critérios de Le Maitre (2002). As abreviações minerais utilizadas neste trabalho seguem as propostas por Whitney \& Evans (2010). O tratamento dos dados estruturais foi realizado no software Stereo32 ${ }^{\circledR}$, e a classificação de dobras adotada é baseada na orientação de linha de charneira e da superfície axial.

\section{Resultados}

\subsection{Caracterização dos litotipos em meso e microescala}

$\mathrm{Na}$ área estudada, representada no croqui esquemático da figura 3, o CPB contém ortognaisses, granitoides e, em menor expressão, anfibolitos. As relações de contato verificadas em campo demonstram que os ortognaisses e os anfibolitos constituem as litologias mais antigas do complexo e são as rochas encaixantes dos granitoides. Os ortognaisses são encontrados na porção centro-norte da área, com xenólitos de anfibolitos associados, enquanto a ocorrência dos granodioritos é expressiva na porção sul, centro-sul, onde formam intrusões concordantes com o bandamento dos gnaisses (Fig. 3A). No extremo norte da área verificou-se a presença de monzogranito intimamente intercalado com ortognaisses e afetados pela mesma fase de dobras. Localmente, são encontrados xenólitos de tamanhos variados de gnaisse e anfibolito contidos nos granitoides, com feições sugestivas de assimilação parcial. Veios micrograníticos, aplíticos e pegmatíticos cortam as litologias, sem controle estrutural aparente.

\subsubsection{Anfibolitos}

Os anfibolitos ocorrem como xenólitos boudinados (Fig. 3A e 3D). São finamente laminados, com textura lepidoblástica e granoblástica, e paragênese mineral composta por $\mathrm{Hbl}+\mathrm{Pl}+\mathrm{Bt}+\mathrm{Qz}$, com zircão e titanita como os principais acessórios. A estrutura principal, uma laminação milimétrica, é definida pelo alinhamento de cristais de hornblenda e biotita, com alternância de porções compostas predominantemente por cristais de plagioclásio e, eventualmente, por cristais de quartzo e hornblenda dispersos (Fig. 4B).

A hornblenda apresenta macla e extinção ondulante (Fig. 4A) e geralmente é bordejada por cristais de biotita, mas também ocorre como cristais subédricos isolados (Fig. 4B). O plagioclásio $\left(\mathrm{An}_{30-35}\right)$ apresenta macla da albita bem desenvolvida, enquanto a macla tectônica é mal definida e observada em poucos cristais, nucleando a partir de suas bordas. A biotita tem ng castanho, apresenta extinção ondulante e kink bands. O quartzo ocorre associadoao plagioclásio em arranjos granoblásticos interlobados ou em interstícios de agregados de hornblenda e biotita (Fig 4A). Extinção ondulante é comum. Cristais esqueletais de titanita são frequentes e estão associados a cristais de biotita.

\subsubsection{Ortognaisses}

Os ortognaisses têm composição tonalítica a diorítica e textura granoblástica fina a média. Os gnaisses tonalíticos são mais expressivos (Fig. 3A e 3B), enquanto o gnaisse diorítico é restrito à porção central da área (Fig 3C). Ambos ocorrem na forma de xenólitos nos granodioritos e apresentam bandamento composicional milimétrico a centimétrico marcado por bandas quartzo-feldspáticas de textura granoblástica e bandas máficas, compostas de biotita e hornblenda (Fig. 3B). O gnaisse tonalítico é composto por $\mathrm{Pl}+\mathrm{Qz}+\mathrm{Bt}+\mathrm{Hbl}+\mathrm{Kfs}$, com 


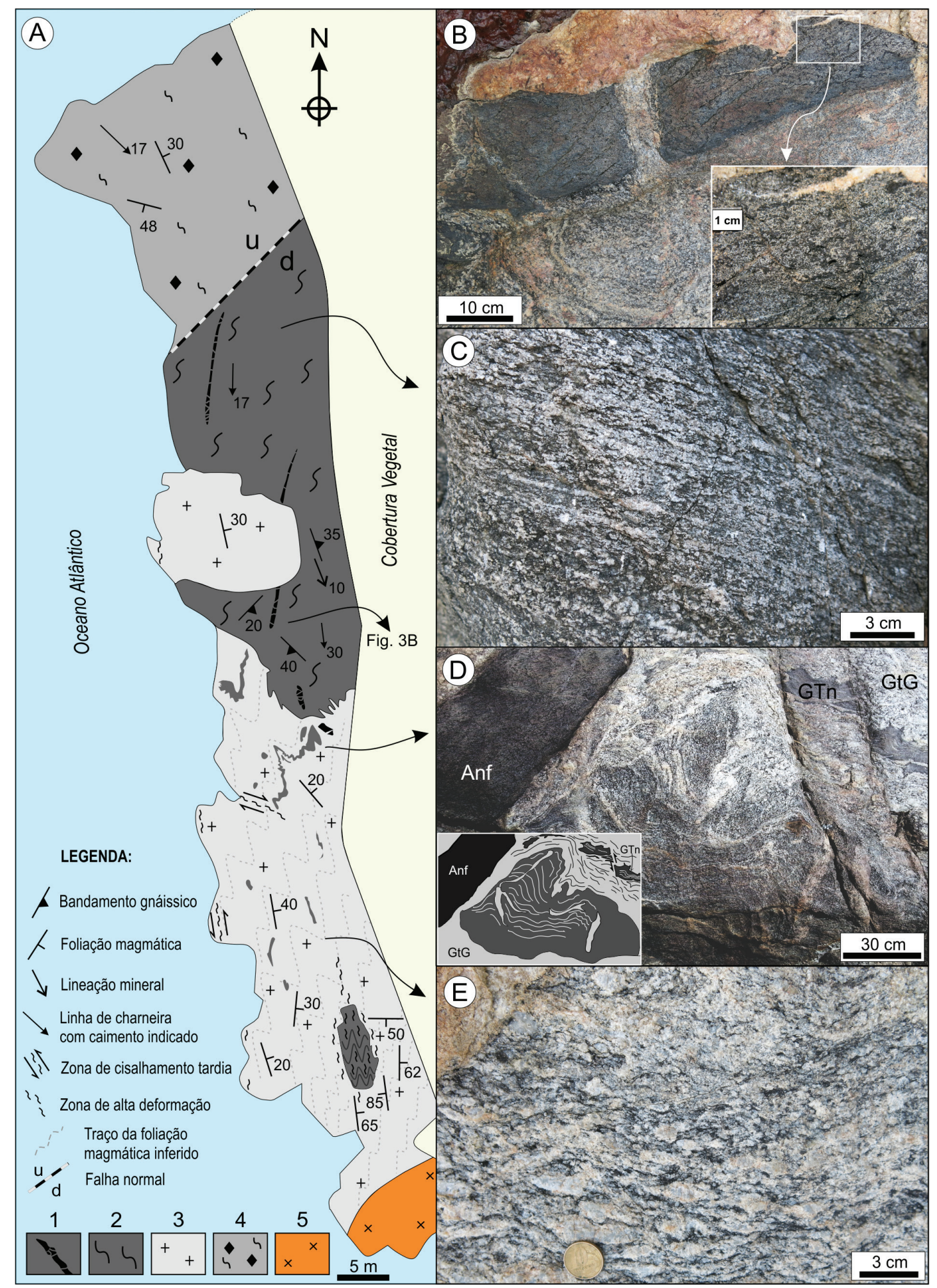

Figura 3. Feições de mesoescala do costão norte da Praia do Cação. A) Mapa esquemático com as litologias e suas principais estruturas: 1 - anfibolito, 2 - ortognaisse, 3 - granodiorito, 4 - hornblenda monzogranito, 5 - Granito Morro dos Macacos; B) Camada de anfibolito boudinada, com detalhe da laminação milimétrica; C) Bandamento do ortognaisse, vista em corte; D) Xenólito de anfibolito e gnaisse diorítico dobrados e parcialmente assimilados pelos granitoides, vista em corte (Anf: anfibolito; GTn: gnaisse tonalítico; GtG: granito-granodiorito); E) Aspecto geral do granodiorito porfirítico, vista em planta.

Figure 3. Mesoscale features of the study area - northern coast of Praia do Cação. A) Sketch showing the distribution of lithological units and structures: 1 - amphibolite, 2 - orthogneiss, 3 - porphyritic granodiorite; 4 - hornblende monzogranite, 5 - Morro dos Macacos Granite; B) Boudinaged amphibolite layer - inset shows the amphibolite mmspaced banding; C) Orthogneiss banding, vertical view; D) Amphibolite and folded dioritic gneiss xenoliths with partial assimilation features, vertical view (Anf: amphibolite; GTn: tonalitic gneiss; GtG: granite-granodiorite); E) General aspect of porphyritic granodiorite, plan view. 
zircão e titanita constituindo as fases minerais acessórias, enquanto o gnaisse diorítico é composto por $\mathrm{Pl}+\mathrm{Bt}+\mathrm{Qz}+\mathrm{Kfs}+\mathrm{Hbl} \pm \mathrm{Cpx}$.

O plagioclásio tem composições $\mathrm{An}_{22-30}$, no gnaisse tonalítico, e $\mathrm{An}_{28-30}$, no gnaisse diorítico, determinadas opticamente. Os cristais são granoblásticos com limites irregulares, possuem inclusões de biotita, hornblenda e plagioclásio, além de abundantes inclusões circulares de quartzo. A macla da albita ébem definida e a macla tectônica é menos frequente e restrita às bordas dos cristais (Fig. 4C e 4D). Extinção ondulante é comum. Junto ao plagioclásio, formando arranjos granoblásticos irregulares, ocorrem cristais de $K$-feldspato com recristalização nas bordas (Fig. 4D), pertitas do tipo filmes e pertitas em chama.

O quartzo forma agregados granoblásticos ameboides, de contatos interlobados, interpretados como resultantes de recristalização por migração de limite de grão (Fig. 4C e 4E). Agregados de padrão granoblástico poligonal são menos comuns (Fig. 4D), assim como feições indicativas de recristalização por bulging no limite de alguns cristais.

A biotita tem ng castanho-avermelhado e geralmente ocorre associada a agregados de hornblenda e a cristais de titanita. (Fig. 4F). Kink bands e extinção ondulante são comumente observadas. A hornblenda tem extinção ondulante e acompanha agregados granoblásticos quartzo-feldspáticos (Fig. 4C e 4E). Nos gnaisses dioríticos, é acompanhada de clinopiroxênio, identificado opticamente como diopsídio, que ocorre de maneira localizada em agregados de textura granoblástica irregular, com inclusões de plagioclásio e quartzo. A titanita ocorre próxima aos agregados de minerais máficos, geralmente associada à biotita (Fig. 4F), e eventualmente apresenta macla simples, segundo o plano cristalográfico $\{100\}$.

\subsubsection{Granodioritos}

Os granodioritos são porfiríticos, localmente heterogranulares, com matriz de textura fina a média composta por quartzo, K-feldspato e agregados de biotita e hornblenda. Os fenocristais são de plagioclásio e K-feldspato, ambos com tamanhos de 1 a $5 \mathrm{~cm}$. A foliação é dada pela orientação preferencial dos fenocristais e dos agregados de minerais máficos (Fig. 3E). A composição varia de hornblenda-biotita granodiorito a biotita granodiorito, e seus minerais acessórios são apatita, zircão e allanita.

O plagioclásio $\left(\mathrm{An}_{18-22}\right)$ geralmente é prismático e subédrico, ocorre em fenocristais e na matriz, com inclusões de biotita e abundantes inclusões de quartzo circular. Apresenta macla polissintética e, em alguns cristais, macla tectônica irregular. Kink bands são comuns, assim como extinção ondulante (Fig. 5A). O K-feldspato ocorre tanto como fenocristais como na matriz, com pertitas em filme pouco desenvolvidas (Fig. 5B). Apresenta macla Carlsbad e macla albita-periclina bem desenvolvidas, além de inclusões de plagioclásio, biotita e quartzo (Fig. 5B). Eventualmente, possui extinção ondulante, subgrãos e apresenta recristalização por rotação de subgrãos nas bordas de alguns cristais. Fraturas extensionais preenchidas por material de mesma composição da matriz são observadas nos fenocristais de plagioclásio e K-feldspato.

O quartzo forma agregados de cristais alongados e contatos irregulares, decorrentes de recristalização por migração de limite de grão (Fig. 5A). Nesses agregados é comum observar o padrão tabuleiro de xadrez residual, formado por subgrãos em duas direções ortogonais (Fig. 5C), recristalização por bulging (Fig. 5A) e textura poligonal localizada. Extinção ondulante e subgrãos prismáticos também são comuns. A biotita tem ng castanho e ocorre em agregados orientados segundo a direção da foliação ou circundando cristais de hornblenda (Fig. 5D). Apresenta kink bands e extinção ondulante, inclusões de zircão com halos pleocroicos, apatita e allanita (Fig. 5D). A hornblenda, quando presente, ocorre em agregados junto com a biotita, onde demonstra feições de desequilíbrio, e apresenta inclusões de quartzo e biotita (Fig. 5D).

\subsubsection{Hornblenda monzogranito}

No norte da área de estudos, predomina uma rocha com textura heterogênea e localmente bandada, com estrutura marcada por variação composicional e textural. Nas 

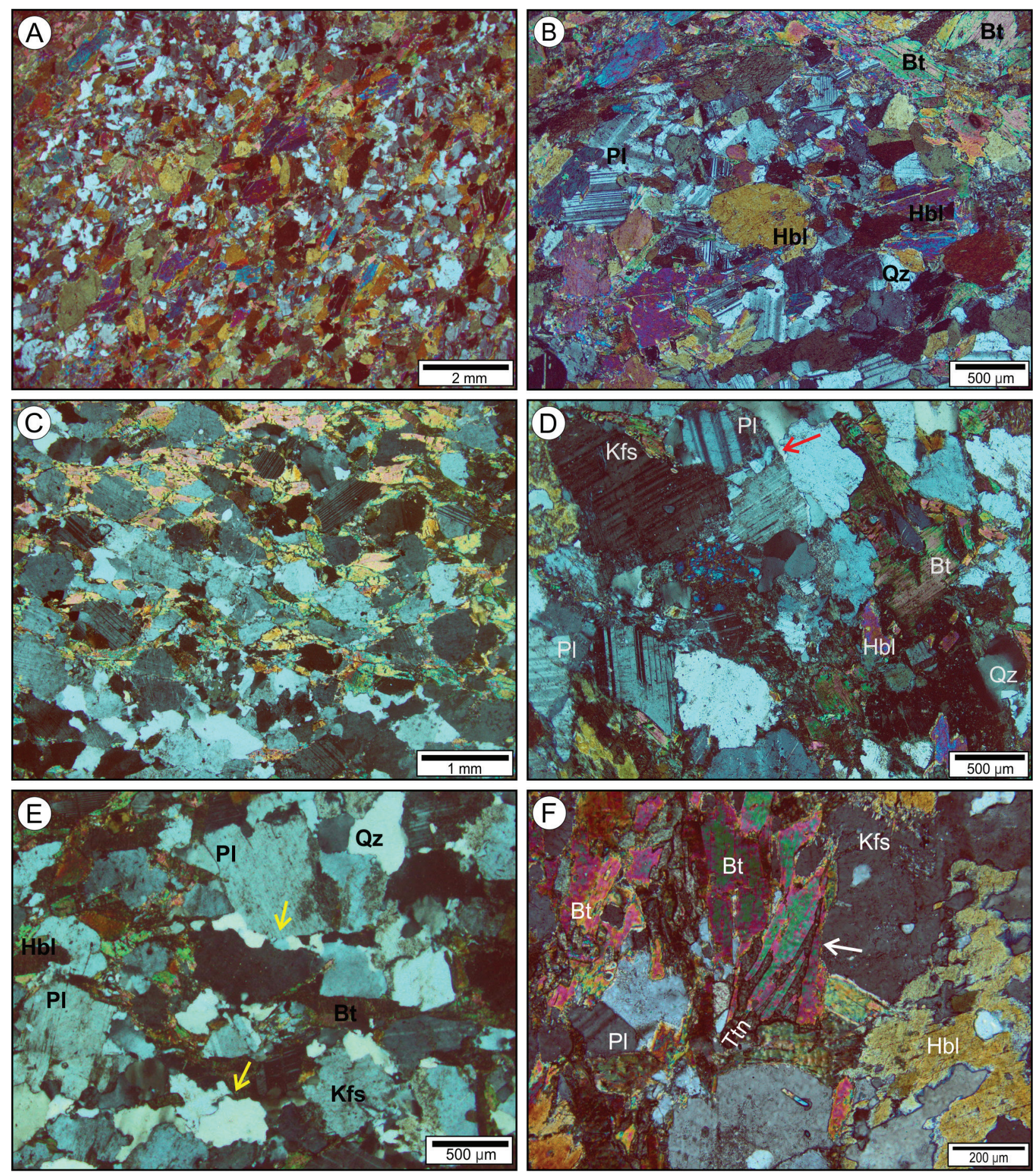

Figura 4. Aspectos petrográficos dos anfibolitos e ortognaisses em luz polarizada. A) Textura do anfibolito dada por agregados de hornblenda e biotita em textura lepidoblástica e granoblástica suturada, e alguns cristais de hornblenda com macla de justaposição; B) Agregados granoblásticos de plagioclásio e cristais subédricos de hornblenda; C) Bandamento irregular no ortognaisse tonalítico, bandas de quartzo em arranjos interlobados, cristais de plagioclásio com macla tectônica e finas bandas de biotita e hornblenda intersticiais; D) Gnaisse diorítico com agregado de quartzo poligonal, no centro da imagem, e recristalização na borda de cristal de K-feldspato, indicado; E) Agregados quartzofeldspáticos em textura granoblástica irregular. Setas amarelas indicam agregados de quartzo anédrico com contatos interlobados, resultantes de recristalização por migração de limite de grão; F) Titanita intercrescida com biotita em gnaisse tonalítico.

Figure 4. Petrographic features of ortogneiss and amphibolite under crossed polars. A) Main amphibolite texture, with lepidoblastic biotite and hornblende aggregates; some hornblende crystals show simple, lamellar twinning; B) Granoblastic plagioclase aggregate and subhedral horblende crystals; $C$ ) Irregular banding in tonalitic gneiss with recrystallized quartz ribbon of interlobate boundaries, and thin band of interstitial biotite and hornblende; D) Dioritic gneiss with granoblastic polygonal quartz aggregate (center of image) and marginal recrystallization of K-feldspar indicated; E) Quartz-feldspar aggregates in irregular granoblastic texture. Yellow arrows indicate anhedral quartz aggregates with interlobate boundaries resulting of grain boundary migration recrystallization; F) Titanite intergrown with biotite in tonalitic gneiss. 

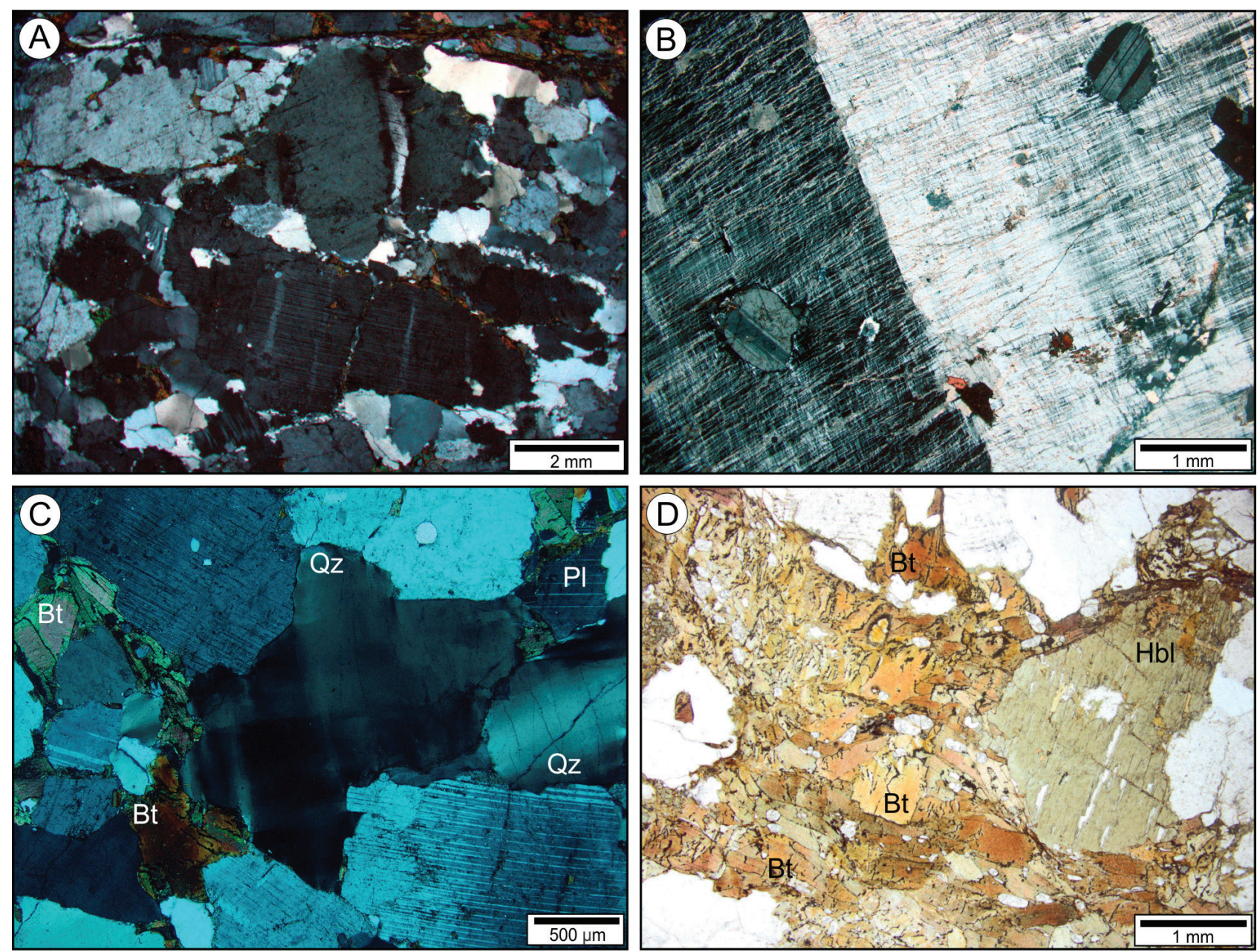

Figura 5. Aspectos petrográficos do granodiorito em luz polarizada, exceto quando indicado. A) Fenocristal de plagioclásio com kink bands, agregados de biotita e quartzo anédrico com recristalização por migração de limite de grão; B) Fenocristal de K-feldspato pertítico com macla Carlsbad e inclusões de plagioclásio e biotita; C) Quartzo anédrico com subgrãos em padrão tabuleiro de xadrez; D) Agregado de cristais de biotita com inclusão de allanita, bordejando cristal de hornblenda; fotomicrografia em luz natural.

Figure 5. Petrographic features of granodiorite, crossed polars (except D). A) Kinked plagioclase phenocryst surrounded by biotite aggregates and anhedral quartz with recrystallization by grain-boundary migration; B) Perthitic K-feldspar phenocryst showing Carlsbad twinning, with plagioclase and biotite inclusions; C) Chessboard pattern subgrains in anhedral quartz; D) Aggregate of biotite with allanite inclusion, surrounded by hornblende crystal; plane polarized light.

bandas de coloração clara e granulação média a grossa a composição corresponde a hornblenda monzogranito (Fig. 3A). As bandas de granulação fina a média e coloração escura apresentam textura metamórfica reliquiar dominante e composição tonalítica. Esse padrão caracteriza a estrutura principal da rocha, que corresponde a um bandamento centimétrico irregular e que muitas vezes encontra-se obliterado. As bandas de hornblenda monzogranito apresentam textura heterogranular, granulação fina a grossa e fenocristais subédricos de hornblenda, são compostas por $\mathrm{Pl}+\mathrm{Kf} s+\mathrm{Qz}+\mathrm{Hbl}+\mathrm{Bt}$. As bandas que preservam a textura metamórfica são compostas por $\mathrm{Hbl}+\mathrm{Bt}+\mathrm{Pl}+\mathrm{Qz}+\mathrm{Kfs}$. Titanita e apatita são os principais minerais acessórios.

O plagioclásio $\left(\mathrm{An}_{28-30}\right)$ forma fenocristais subédricos, em geral com limites difusos e macla tectônica fina. Ocorre junto a cristais de $K$-feldspato, que geralmente apresentam pertitas em chamas e extinção ondulante. O quartzo é intersticial, com extinção ondulante e subgrãos em padrão tabuleiro de xadrez. A hornblenda ocorre como fenocristais e cristais intersticiais entre agregados quartzo-feldspáticos, apresenta macla simples e inclusões de biotita e apatita. A biotita tem ng castanho e ocorre de forma intersticial ou em agregados com hornblenda. 


\subsection{Relações estruturais no Complexo Porto Belo}

As principais estruturas planares na área de estudo são o bandamento gnáissico, nos ortognaisses, e a foliação magmática, nos granitoides. Essas estruturas, no entanto, têm suas geometrias originais modificadas por dobramentos.

O bandamento gnáissico $\left(S_{b}\right)$ tem direção predominante NE-SW, com variações locais para NW-SE, e mergulhos de baixo ângulo para SE, NE e SW, respectivamente (Fig. 6A). A lineação mineral $\left(L_{m}\right)$ é marcada pelo alinhamento dimensional de cristais de biotita, e tem baixo ângulo de caimento para SSE e NNW. A lineação de estiramento $\left(L_{x}\right)$ é mal desenvolvida e, quando observada, é paralela à lineação mineral.

A foliação magmática do granodiorito $\left(\mathrm{S}_{0}\right)$ (Fig. 6B) tem direção N-S, com poucas variações locais para e NNE-SSW. O ângulo de mergulho é geralmente baixo a moderado, com predomínio de sentido para leste e variações para ESE. Localmente, a foliação magmática encontra-se verticalizada, com direção NNW-SSE e mergulho para ENE.

Dobras isoclinais e dobras apertadas, de escala centimétrica a decimétrica, afetam o bandamento gnáissico e a foliação magmática, com morfologia distinta em cada litologia. Enquanto as dobras que afetam os ortognaisses são isoclinais recumbentes (Fig. 7A), as dobras nos granitoides são tipicamente horizontais mergulhantes (Fig. 7B).

As dobras isoclinais recumbentes afetam o bandamento gnáissico e frequentemente apresentam um espessamento na zona de charneira (Fig. 7A e 7C). Os planos axiais têm direção NE-SW, com mergulhos de baixo ângulo para sudeste. Os planos axiais têm direção NESW, com mergulhos moderados para sudeste, enquanto os eixos têm baixo caimento variando para sul e sudeste (Fig. 6C). A foliação plano-axial relacionada a este dobramento $\left(\mathrm{S}_{2}\right)$ é discreta.

As dobras horizontais inclinadas, registradas nos granitoides, são apertadas e assimétricas (Fig. 6B). Seus planos axiais têm direção NW-SE com mergulhos moderados para $\mathrm{NE}$, e eixos sub-horizontais com caimento para
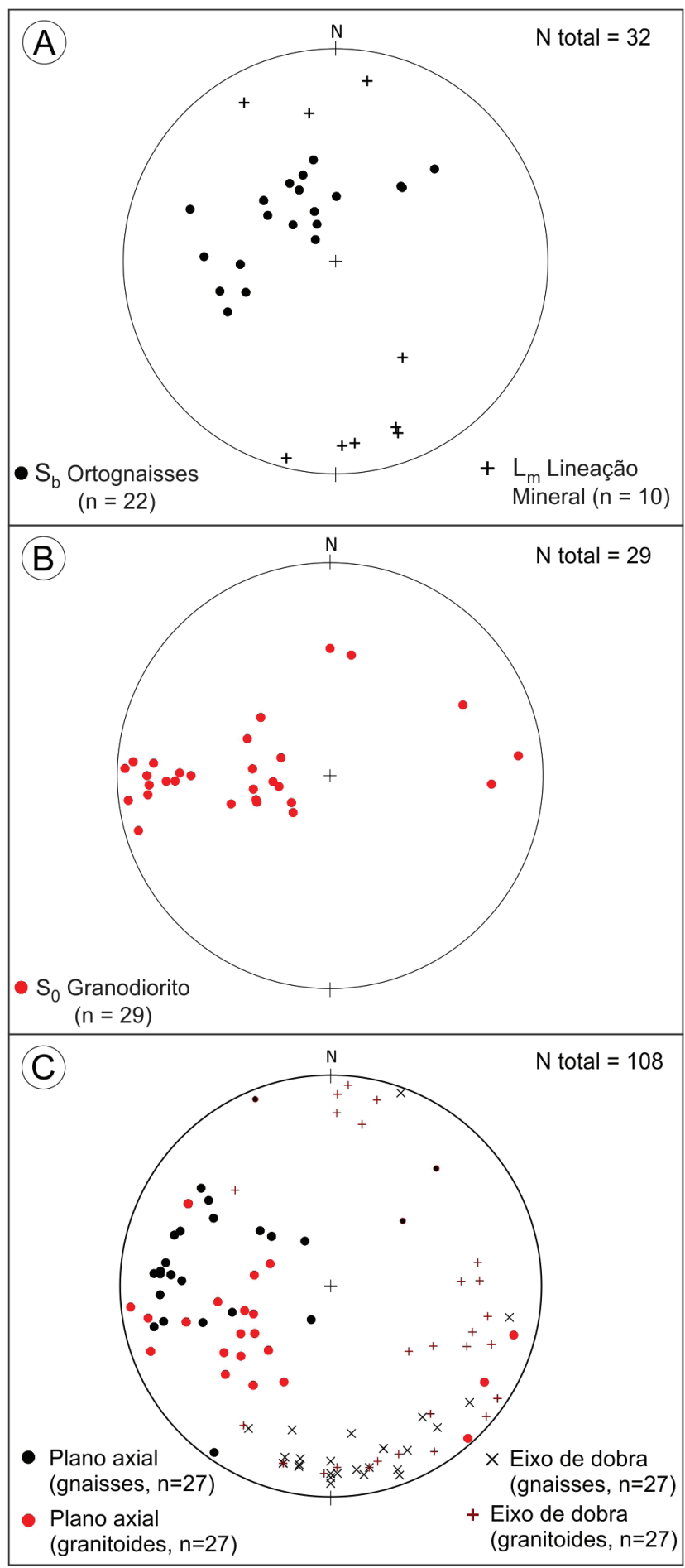

Figura 6. Dados estruturais do Complexo Porto Belo em projeção estereográfica equiárea, hemisfério inferior. A) Polos de planos de bandamento gnáissico e lineação mineral $\left(L_{m}\right)$ dos ortognaisses tonalíticos e dioríticos; $B$ ) Polos de planos de foliação magmática dos granodioritos; C) Polos de planos axiais de dobras e suas respectivas linhas de charneira; símbolos vermelhos referem-se aos granitoides (granodiorito e monzogranito) e símbolos pretos aos gnaisses.

Figure 6. Structural data for the Porto Belo Complex in stereographic, lower-hemisphere equal area projection. A) Poles to gneissic banding and mineral lineation $(\mathrm{Lm})$ of tonalitic and dioritic orthogneisses; B) Poles to magmatic foliation in granitoids; C) Fold axes and poles to axial planes; red for granitoids (granodiorite and monzogranite), black for gneisses. 
SE (Fig. 6C). Uma variação pontual é observada na porção sul da área, onde os planos axiais são subverticais com direção N-S e eixos subhorizontais com caimento para $\mathrm{N}$.

Dobras parasíticas são abundantes em ambas as litologias, com morfologia em $S$, M, e Z (Fig. 7D). A geometria dessas dobras é definida por planos axiais de direção NE-SW com mergulhos moderados para $S E$, e eixos de baixo caimento para SW. Dobras ptigmáticas têm ocorrência pontual, em veios leucocráticos nos ortognaisses. As superfícies axiais e seus respectivos eixos seguem o mesmo padrão geométrico das dobras parasíticas.

A camada de anfibolito, originalmente contínua, encontra-se fragmentada em boudins retangulares (Fig. 3B). Os eixos de maior extensão dos boudins, observados no afloramento, são paralelos aos eixos das dobras ptigmáticas e parasitas, com direção NE-SW.

A assimetria das dobras, tanto nos ortognaisses como nos granitoides, define vergência de topo para SW (Fig. 7B e 7C). A rotação de xenólitos de ortognaisses inclusos nos granitoides demonstram movimento de topo para NW (Fig. 7E). Nos granodioritos, os porfiroclastos assimétricos indicam movimento do topo para NW.

Estruturas tardias afetam a área, representadas por uma zona de cisalhamento pouco espessa de direção NS e cinemática transcorrente sinistral na parte oeste da área. A geração de milonitos é restrita a uma faixa centimétrica e uma ramificação desta zona é responsável pela verticalização das principais estruturas planares $\left(S_{0}, S_{b}\right)$ e dos planos axiais das dobras, conforme observado no extremo sul da área (Fig. 3A e 7F). Outras ramificações, com direção NW-SE, transectam as litologias e arrastam localmente a foliação magmática e o bandamento gnáissico. Na porção norte da área, encontra-se uma falha normal de direção $050^{\circ}$ 230, responsável pelo soerguimento do bloco noroeste (Fig. 3A).

\subsection{Feições de fusão parcial no Complexo Porto Belo}

Feições típicas de leucossoma in situ, leucossoma in source e veios de leucossoma (leucossoma in vein) são identificadas nos gnaisses estudados. As feições de leucossoma in situ e in source são comumente observadas ao longo do bandamento gnáissico e são reconhecidas devido à sua heterogeneidade textural (Fig. 8A). Geralmente, a presença de leucossoma realça o bandamento gnáissico, deixando-o mais espesso do que era originalmente (Fig. 8A). Os veios de leucossoma têm espessura centimétrica, frequentemente são conectados ao bandamento gnáissico e, quando adquirem mobilidade, tendem a cortá-lo. A coalescência destes veios desenvolve uma rede de venulações leucograníticas (Fig. 8B).

Os anfibolitos registram a anatexia a partir de pequenos patches (manchas), bolsões e veios de leucossoma discordantes. Geralmente, as camadas de anfibolito são fragmentadas e preenchidas por leucossoma, que auxilia na sua desagregação (Fig. 8C). O acúmulo de leucossoma em zonas dilatativas, como o espaço inter-boudins, é comum.

Nos granodioritos, as feições de fusão parcial são identificadas como veios e bolsões centimétricos. Os veios são discordantes da foliação principal $\left(S_{0}\right)$, têm contatos difusos e contêm hornblenda euédrica a subédrica (Fig. 8D). Os bolsões de leucossoma possuem contatos difusos, são discordantes da foliação e apresentam hornblenda euédrica a subédrica, geralmente alinhadas em agregados. (Fig. 8E).

Os neossomas têm composição monzogranítica, compostos essencialmente por plagioclásio, hornblenda, quartzo e K-feldspato, com textura heterogranular fina a média. Quando o neossoma é mais expressivo, como ocorre no extremo norte da área, corresponde a hornblenda monzogranitos (Fig. 3A), mas mesmo nestes casos ainda é possível identificar as estruturas do protólito (Fig. 8F).

Ao microscópio, lentes milimétricas de leucossoma in source são observadas ao longo do bandamanto gnáissico (Fig. 9A). Os minerais consumidos na reação de fusão apresentam bordas corroídas e geralmente têm contatos difusos. Essas feições são observadas principalmente em cristais de biotita e hornblenda, mas também ocorrem em cristais de plagioclásio 

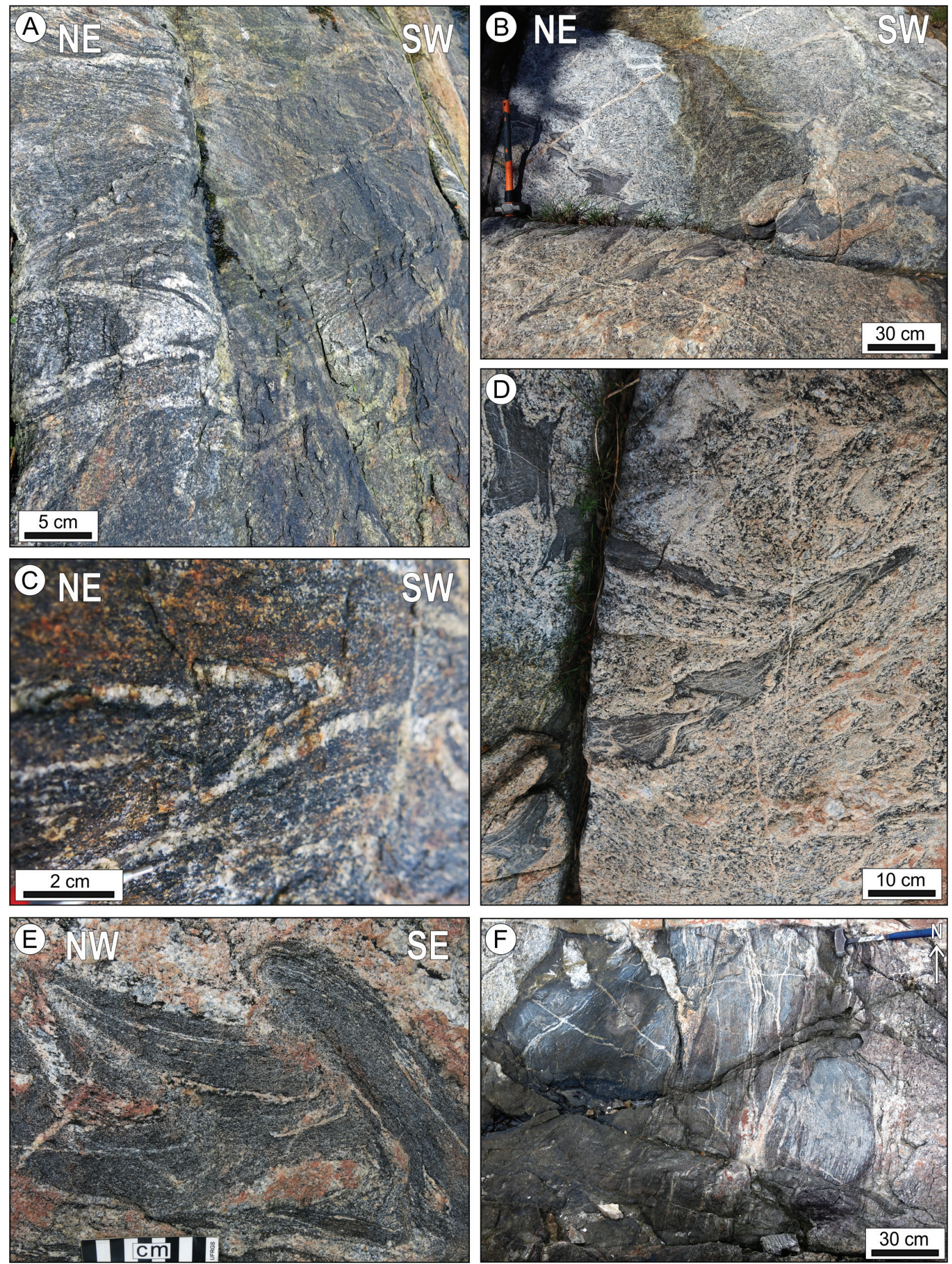

Figura 7. Estruturas de mesoescala dos ortognaisses e granodioritos do CPB. A) Dobra recumbente com charneira espessada em gnaisse tonalítico, vista em corte; B) Dobras horizontais mergulhantes, assimétricas, afetando o granodiorito porfirítico e xenólitos de gnaisses; C) Dobra de arrasto em gnaisse tonalítico indicando movimento de topo para SW, vista em corte; D) Dobras parasíticas em padrão S, M e Z; E) Xenólito de ortognaisse no granodiorito, com indicador cinemático de topo para NW, vista em corte; F) Dobras verticais em fragmento métrico de ortognaisse no granodiorito porfirítico.

Figure 7. Mesoscale structures of orthogneiss and granodiorite of Porto Belo Complex. A) Thickened-hinge, recumbent fold in tonalitic gneiss - cross section; B) Asymmetric, horizontal inclined folds in porphyritic granite with gneiss xenoliths folded together; $C)$ Drag fold in tonalitic gneiss indicating top-to-the-SW shear sense, cross section; D) S-, M- and Z-symmetry parasitic folds; E) Partially assimilated orthogneiss xenolith in porphyritic granodioritic, with top-tothe-NW shear sense; cross section. F) Upright folds in $\mathrm{m}$-size orthogneiss fragment within the porphyritic granodioritic. 

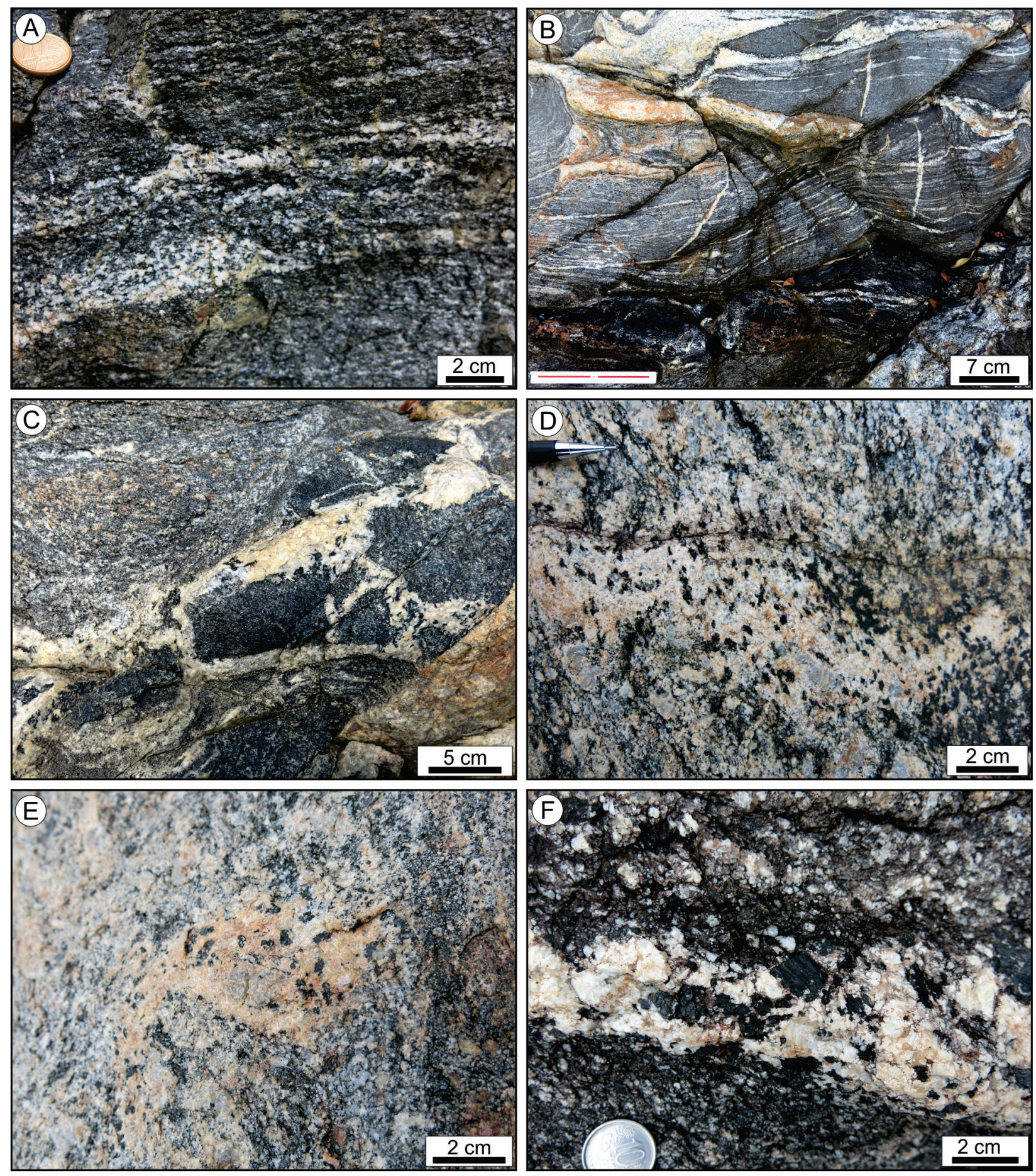

Figura 8. Evidências meso- e macroscópicas de fusão parcial; vista em planta, exceto quando indicado. A) Bandamento gnáissico realçado por leucossoma in situ e in source, vista em perfil; B) Rede de venulações formada pela coalescência de leucossoma in source, cortando o bandamento gnáissico; C) Xenólitos de anfibolito no gnaisse imersos em leucossoma; D) Veio discordante e de contatos difusos no granito porfirítico, com hornblenda euédrica a subédrica; E) Bolsão de fusão (melt pocket) no granito porfirítico, com contato difuso e agregados alongados e alinhados de hornblenda euédrica a subédrica; F) Banda de horblenda monzogranito (neossoma) em paleossoma tonalítico, vista em perfil.

Figure 8. Evidence of partial melting at meso and microscale; plan view, except where indicated. A) Gneissic banding enhanced by in situ and in source leucosome, cross section; B) Network of veins formed by coalescence of in source leucosome crosscut the gneissic banding; C) Amphibolite xenoliths immerse in leucosome; D) Discordant hornblendebearing vein of diffuse boundaries in the porphyritic granite, hornblende crystals are euhedral to subhedral; E) Melt pocket with euhedral hornblende crystals and diffuse boundaries in the porphyritic granite; F) Hornblende monzogranite (neosome) in paleosome, cross section. 
(Fig. 9B). Observam-se também contatos em cúspides entre cristais de plagioclásio, marcados pela presença de quartzo. Nos anfibolitos, bolsões de fusão (melt pockets) são realçados pela presença de minerais reagentes envolvidos por quartzo com bordas difusas (Fig. 9C).

As microestruturas relacionadas com a cristalização de neossoma são caracterizadas pela geração de minerais euédricos, com crescimento parcial ou total no líquido anatético. No neossoma, a formação de cristais euédricos e subédricos compreende hornblenda, plagioclásio e, pontualmente, titanita (Fig. 9D e 9E). Plagioclásio e K-feldspato geralmente formam cristais subédricos. O sobrecrescimento de plagioclásio em cristais de plagioclásio mais antigos representa outra feição típica do processo de fusão parcial, com cristalização de neossoma nos interstícios.

\section{Discussão}

\subsection{Condições de deformação e metamorfismo}

Microestruturas de deformação de média e alta temperatura são verificadas nos litotipos estudados. Segundo Passchier \& Trouw (2005), em temperaturas médias $\left(450-600{ }^{\circ} \mathrm{C}\right)$ é comum a recristalização por rotação de subgrãos em cristais de quartzo e feldspatos, além do desenvolvimento de pertita em chamas neste último. Stipp et al. (2002a) demonstram que a recristalização por mecanismo de migração de limite de grão em cristais de quartzo pode indicar temperaturas de 500 a $700{ }^{\circ} \mathrm{C}$. Já a geração de subgrãos ortogonais no quartzo, implicando deslizamento nos sistemas basal-a e prismático-c, que forma o padrão tabuleiro de xadrez, é tomada como um marcador térmico da ordem de $650{ }^{\circ} \mathrm{C}$ (Kruhl, 1996; Stipp et al., 2002a, 2002b).

Nos ortognaisses, constatou-se que a assembleia mineral e a neoformação de minerais, como clinopiroxênio, em conjunto com a recristalização no quartzo e K-feldspato (Fig. 4C e 4D), podem auxiliar na determinação de condições termais para o metamorfismo. A recristalização por rotação de subgrão presente na borda de cristais de K-feldspato e a recristalização por migração de limite de limite de grão em bandas de quartzo indicam deformação de média a alta temperaturas. Mesmo com feições relictas dos protólitos ígneos e transposições de estruturas pela fusão parcial, a paragênese mineral e a análise microestrutural apontam que o metamorfismo ocorreu em temperaturas médias a altas. A relação destes fatores sugere que as condições de metamorfismo dos ortognaisses, e anfibolitos, são compatíveis com as da fácies anfibolito médio a superior, e corroboram com as condições previamente descritas por outros autores (e.g. Silva, 1991; Chemale Jr. et al., 1995; Bitencourt, 1996; De Toni et al., 2020a, 2020b).

A presença de cristais de quartzo com subgrãos em padrão tabuleiro de xadrez no granodiorito demonstra que a deformação ocorreu em altas temperaturas, em torno de $650^{\circ}$ C. Este marcador pode ser um indicativo de que a deformação foi sincrônica à sua cristalização, dado que a temperatura é compatível com a da solidus de magmas graníticos, bem como pode apenas indicar deformação em alta temperatura. No entanto, feições como as microfraturas extensionais seladas pela matriz, encontradas em cristais de plagioclásio e K-feldspato, são características comuns de condições magmáticas, como descrito por Büttner (1999). Os aspectos microestruturais de alta temperatura, em conjunto com as texturas ígneas preservadas nos granodioritos, são indicativos de que a deformação ocorreu ao longo de sua cristalização e sugerem seu caráter sintectônico.

A deformação é sincrônica ao metamorfismo dos protólitos ígneos (tonalitos e dioritos) em fácies anfibolito médio a superior, o qual gerou o bandamento gnáissico de baixo ângulo de mergulho. As intrusões graníticas têm seu posicionamento ao longo de zonas de fraqueza representadas pelo bandamento gnáissico. Como as intrusões registram essa deformação ao longo de sua cristalização, depreende-se que seu posicionamento se superpõe, ao menos em parte, com o evento metamórfico na região estudada.

O desenvolvimento de morfologias distintas nas dobras dos ortognaisses e dos granitoides evidencia o caráter heterogêneo e progressivo da deformação que, neste caso, é dado pela 

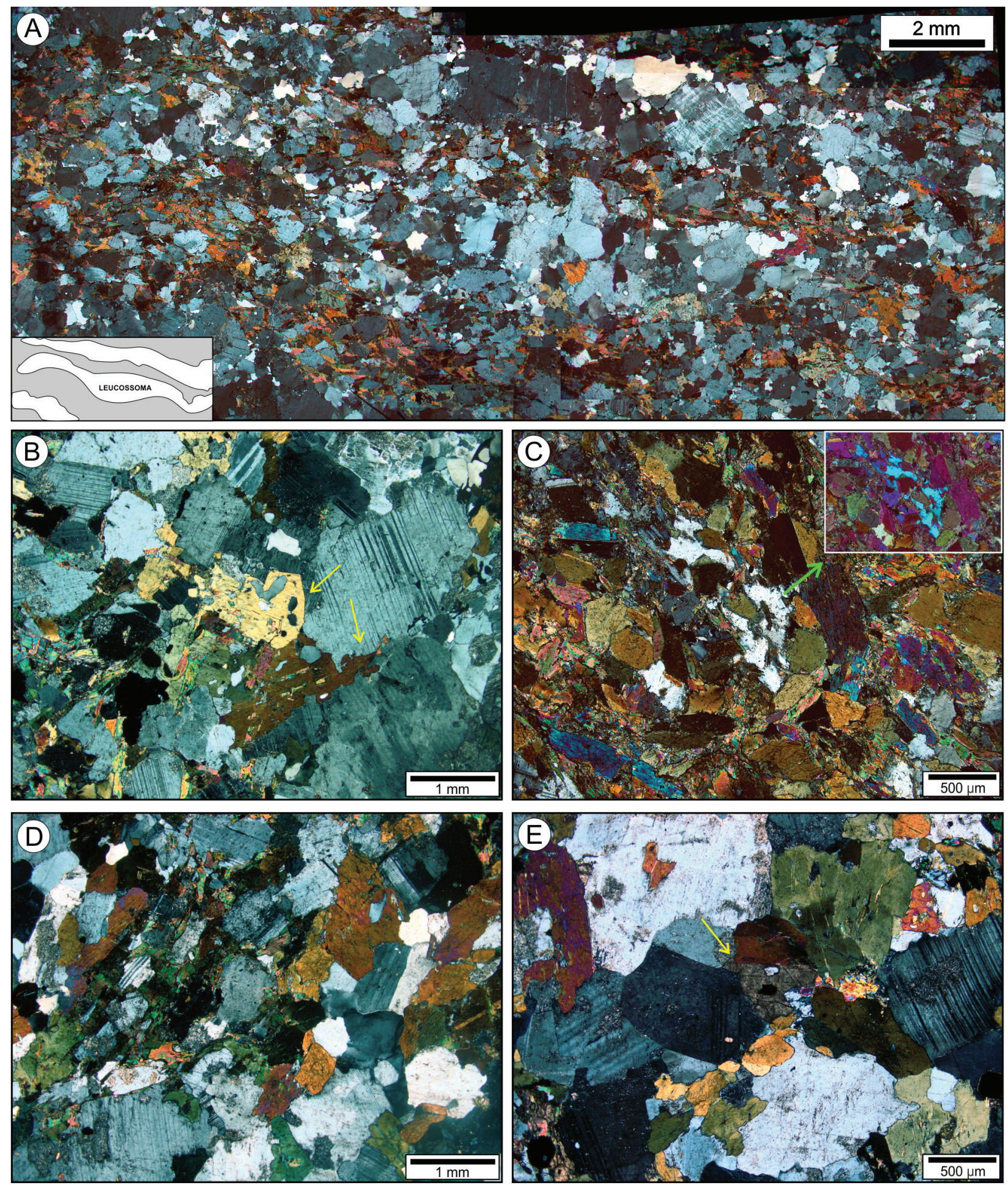

Figura 9. Microestruturas relacionadas à fusão parcial, em luz polarizada. A) Lentes milimétricas de leucossoma in source no bandamento do ortognaisse tonalítico, com desenho esquemático para realçar as feições de interesse; B) Textura resultante da reação de consumo de cristais de hornblenda com bordas corroídas, e de cristais de plagioclásio, com contatos irregulares e difusos; ambas as feições indicadas; C) Bolsão de fusão (melt pocket) em anfibolito com fragmentos de cristais irregulares de hornblenda e biotita, em detalhe a mesma feição com a placa de gipso inserida; D) Cristais de hornblenda, plagioclásio e quartzo no neossoma; E) Cristais de titanita e hornblenda em neossoma.

Figure 9. Microstructures related to partial melting; crossed polars. A) Mm-thick lenses of in source leucosome along the banding of tonalitic gneiss; B) Textures resulting of hornblende-consuming reaction, showing corroded rims, and plagioclase crystals of irregular and diffuse boundaries; C) Melt pocket in amphibolite with hornblende and biotite crystals; inset shows detail with gypsum plate inserted; D) Hornblende, plagioclase and quartz in neosome; E) Titanite and hornblende crystals in neosome. 
resposta reológica de cada litologia ao campo tensional. As dobras isoclinais recumbentes nos ortognaisses apresentam uma variação no caimento dos seus eixos, de sudeste para sul, que pode indicar seu caráter não cilíndrico (Fig. 6C). Essas dobras desenvolvem uma foliação de plano axial discreta que é obliterada pela intrusão dos granitoides ao longo destes planos. Estes, por sua vez, registram a deformação em dobras assimétricas (Fig. 6B e 6C) de ordem mais baixa que as dobras parasitas, de morfologias $Z, \mathrm{M} \mathrm{e}$ $S$ dos ortognaisses. Ainda assim, o registro da geometria de baixo ângulo dos ortognaisses pode ser parcialmente recuperado no flanco longo das dobras horizontais inclinadas dos granitoides.

Apesar das diferenças morfológicas nas dobras do CPB, suas vergências são concordantes e indicam transporte para SW. Outros indicadores cinemáticos, como xenólitos rotacionados, indicam movimento de topo para NW (Fig. 7D e 7E), compatível com o sentido do transporte tectônico da colisão continental no Cinturão Dom Feliciano referido por diversos autores (Martil, 2016; Passareli et al., 2018). A variação na vergência das dobras pode ser explicada pelo aspecto não cilíndrico das mesmas, ou simplesmente pela partição da deformação ao longo de zonas de cavalgamento (Evans \& Dunne, 1991; Dittmar et al., 1994; Jones \& Tanner, 1995). Contudo, a presença de indicadores cinemáticos confiáveis, como fragmentos rotacionados de gnaisses e porfiroclastos assimétricos nos granitoides, demonstra geometrias compatíveis com a movimentação principal da máxima convergência, de direção NW-SE com transporte tectônico para NW.

\subsection{Fusão parcial no Complexo Porto Belo}

Embora as feições indicativas de fusão parcial sejam amplamente observadas nas litologias mapeadas do CPB, o volume de líquido anatético gerado é pouco expressivo. A geração de líquidos anatéticos é marcada por feições de leucossoma in situ, registrada em pequenos bolsões de fusão e em lentes ao longo do bandamento gnáissico (Fig. 8A e 8E). Localmente, quando esses líquidos adquirem mobilidade, progridem para feições de leucossoma in source, definidas por lentes de leucossoma que, conforme coalescem, cortam as estruturas planares principais $\left(\mathrm{S}_{\mathrm{b}}\right.$ e $\left.\mathrm{S}_{0}\right)$ e formam uma rede de venulações (Fig. 8B e 8D).

O controle estrutural da fusão parcial é limitado, sem atuação significativa na canalização e transporte de líquido anatético ao longo de estruturas. No entanto, é responsável pelo acúmulo de líquido em zonas dilatativas, como zonas de charneira de dobras e zonas inter-boudins (Fig. 7F e 8C). Como a coalescência destes líquidos é condicionada a partir do bandamento gnáissico e de estruturas dilatativas, é possível que a fusão parcial seja relativamente tardia em relação à gênese do bandamento gnáissico e das dobras principais. Interpreta-se, portanto, que a fusão parcial das rochas do CPB é tardi-deformacional.

Além de contribuir para a baixa mobilidade dos líquidos anatéticos, o fraco controle estrutural também pode ter resultado na baixa penetratividade da fusão parcial, uma vez que as principais estruturas dos protólitos encontramse preservadas. 0 baixo volume de neossoma gerado, a ampla preservação das estruturas do protólito e o predomínio de feições de leucossoma in situ e in source justificam a classificação dos migmatitos do CPB como metatexitos.

A presença de cristais de biotita, hornblenda e plagioclásio com contatos corroídos e arredondados sugere que estes são os principais minerais reagentes na reação de fusão parcial. Um dos resultados comuns neste processo corresponde ao produto sólido desta reação, denominado mineral peritético (Sawyer, 2008; Vernon, 2011; Erdmann et al., 2012; Weinberg \& Hasalová, 2015). No caso das rochas do CPB, um dos principais marcadores da fusão parcial é a geração de hornblenda peritética (Fig. 8C, 8D, 8E, 8F).

A ocorrência de hornblenda como a fase peritética, em cristais isolados ou agregados, é descrita por alguns autores (e.g. Sawyer, 2010; Weinberg \& Hasalová, 2015; Martini et al., 2019b) como diagnóstica em processos de fusão parcial assistida por água (water-fluxed melting). Adicionalmente, as rochas do Complexo Porto Belo apresentam temperaturas de metamorfismo incompatíveis com a fusão gerada por quebra de 
minerais hidratados (dehydration melt) a partir de biotita ou hornblenda. Neste caso, a presença de fluidos aquosos, mesmo que em quantidades pequenas, seria imprescindível para desencadear as reações de fusão parcial nas rochas do CPB.

\subsection{Comparação das feições estruturais nas rochas do embasamento a norte e a sul da Zona de Cisalhamento Major Gercino}

Zonas de cisalhamento constituem um dos principais canais de fluidos da crosta, assim como controlam a geração e posicionamento de magmas (Brown, 2007). Em áreas adjacentes a estas zonas é comum observar o registro de fusão parcial assistida por água, visto que elas funcionariam como canais para infiltração de água na crosta (Sawyer, 2010). A intensa atividade tectônica dessas zonas de cisalhamento, e o fato de canalizarem o transporte e acumulação de líquidos magmáticos, inibe o processo de fusão parcial em seu interior e, assim, a anatexia tende a ocorrer preferencialmente nas áreas adjacentes. No caso da ZCMG, dados preliminares demonstram que no seu interior as rochas do CPB não apresentam registro de fusão parcial, conforme apontado por Andres \& Bitencourt (2018). No entanto, as áreas adjacentes registram a ocorrência de migmatitos, como é observado no Complexo Porto Belo, na área do presente estudo, e no Complexo Camboriú, a norte.

O escape de água do interior da ZCMG para regiões adjacentes, como a sul onde se encontra o CPB, pode ter constituído uma das principais fontes de água para o processo de fusão parcial. Outro fator significativo é o magmatismo precoce associado à ZCMG, marcado pelos Granitoides de Quatro Ilhas, que possui contribuição de magmas básicos (Florisbal et al., 2012b), e poderiam ter atuado como fontes de calor para o aumento de temperatura das rochas encaixantes e, assim, favorecido o desenvolvimento da fusão parcial nas rochas do CPB. Esses aspectos, além da presença de hornblenda peritética, permitem conjecturar um cenário de fusão assistida por água para estas rochas possivelmente associado com a atividade tectônica e magmática da Zona de Cisalhamento Major Gercino.

Por outro lado, o volume e intensidade da anatexia observados a norte da ZCMG, no Complexo Camboriú, são mais expressivos, e seus migmatitos são definidos como diatexitos. Segundo Martini et al. (2019b), a mobilidade do líquido anatético no CC tem amplo controle estrutural, desenvolvendo-se a partir de zonas de cisalhamento sin-magmáticas que evoluem de maneira progressiva para diques leucograníticos verticais, que caracterizam um volume expressivo de magma. Estes autores também definem que as condições e gênese da anatexia no CC são decorrentes de fusão assistida por água.

Embora o volume de líquido anatético registrado na região a sul da ZCMG seja muito menor que o volume presente nas rochas a norte, as feições observadas na área de estudo não deixam dúvida quanto à atuação de processos de fusão parcial, provavelmente assistida por água, nesta região. Como a área de exposição do embasamento estudado é muito restrita, é possível que tais feições venham a se tornar mais significativas se encontradas em áreas maiores ainda não estudadas ao sul da ZCMG, atualmente consideradas como pertencentes ao Complexo Águas Mornas (e.g. Silva et al., 2005).

\section{Conclusões}

Os aspectos estruturais do Complexo Porto Belo na porção situada fora dos limites da Zona de Cisalhamento Major Gercino correspondem ao registro de uma tectônica de baixo ângulo, que retrata um importante estágio da evolução crustal em regimes transpressivos, uma vez que antecede a tectônica transcorrente e compõe a fase inicial dos movimentos de empurrão que, neste caso, são correlatos à colisão continental durante o Ciclo Brasiliano/Panafricano.

As condições de deformação e metamorfismo demonstram temperaturas de fácies anfibolito médio a superior para os eventos registrados na região estudada. As intrusões graníticas ocorrem ao longo do bandamento gnáissico, e são posicionadas no final do evento metamórfico. A deformação é contracional, com uma componente de encurtamento de direção NW-SE. Indicadores cinemáticos, como xenólitos rotacionados e porfiroclastos assimétricos nos granodioritos, atestam movimentos de topo 
para NW (Fig. 7E), compatíveis com o transporte tectônico da máxima convergência associada ao estágio colisional do Ciclo Brasiliano/ Panafricano (e.g. Martil, 2016; Martil et al., 2017; De Toni et al., 2020a, 2020b). Mesmo assim, deve-se considerar que a área estudada neste trabalho corresponde a uma faixa estreita de rochas do Complexo Porto Belo e, desta forma, interpretações com implicações regionais podem não ser representativas nesta escala.

As principais feições diagnósticas de fusão parcial no CPB são observadas ao longo do bandamento gnáissico, em pequenos bolsões de leucossoma e veios discordantes de contato difuso. Uma das principais características do neossoma é a presença de cristais de hornblenda peritética. Os líquidos gerados pela fusão parcial possuem controle estrutural pouco expressivo e tendem a acumular-se em zonas de charneira de dobras e zonas inter-boudins, que evidenciam seu caráter tardi-tectônico. A ampla preservação das estruturas do protólito justifica a classificação de metatexitos para estes migmatitos. A contribuição da fusão parcial do Complexo Porto Belo na geração dos magmas graníticos da região é desconhecida e sua investigação pode fomentar futuros trabalhos.

Evidências de fusão parcial são encontradas em rochas pré-colisionais neoproterozoicas ao longo do Cinturão Dom Feliciano. Além do Complexo Porto Belo, a presença de migmatitos é descrita em orto- e paragnaisses do Complexo Cerro Olivo (CCO), no Uruguai (Lenz et al., 2011, 2013; Masquelin et al., 2012), e em orto- e paragnaisses do Complexo Várzea do Capivarita (CVC), no Rio Grande do Sul (Silva et al., 2008; Martil et al., 2017). Além disso, as idades neoproterozoicas, ca. $770-800 \mathrm{Ma}$ para o CCO e 790 Ma para o CVC, definidas para o magmatismo pré-colisional de arco magmático representado por essas associações, são semelhantes à idade do CPB de ca. 800 Ma (De Toni et al., 2020a). Dessa maneira, o CPB é aqui interpretado como mais um exemplo de rochas pré-colisionais neoproterozoicas que registram fusão parcial durante o estágio pós-colisional no Cinturão Dom Feliciano.
Agradecimentos. As autoras gostariam de agradecer ao CNPq (processo 442812/2014-0) pelos recursos destinados à pesquisa.

\section{Referências}

Andres, F.G. \& Bitencourt, M.F. 2018. Caracterização estrutural do Complexo Porto Belo: o embasamento da Zona de Cisalhamento Major Gercino em Bombinhas, SC. In: $49^{\circ}$ CONGRESSO BRASILEIRO DE GEOLOGIA, 2018, Rio de Janeiro. Anais do $49^{\circ}$ Congresso Brasileiro de Geologia, Rio de Janeiro, SBG, p. 993.

Basei, M.A.S., Campos Neto, M.D.C., Lopes, A.P., Nutman, A.P., Liu, D. \& Sato, K. 2013. Polycyclic evolution of Camboriú Complex migmatites, Santa Catarina, Southern Brazil: integrated $\mathrm{Hf}$ isotopic and $\mathrm{U}-\mathrm{Pb}$ age zircon evidence of episodic reworking of a Mesoarchean juvenile crust. Brazilian Journal of Geology, 43: 427443.

Bitencourt, M.F. 1996. Granitoides sintectônicos da região de Porto Belo, SC: uma abordagem petrológica e estrutural do magmatismo em zonas de cisalhamento. Porto Alegre, 310p. Tese de Doutorado, Programa de Pósgraduação em Geociências, Instituto de Geociências, Universidade Federal do Rio Grande do Sul.

Bitencourt, M.F. \& Kruhl, J.H. 2000. Crustal-scale shearing, magmatism and the development of deformation structures: an example from Santa Catarina (Southern Brazil). Zeitschrift für Angewandte Geologie, 229-236.

Bitencourt, M.F. \& Nardi, L.V.S. 1993. Late- to post-collisional Brasiliano magmatism in southermost Brazil. Anais da Academia Brasileira de Ciências, 65: 4-16

Bitencourt, M.F. \& Nardi, L.V.S. 2000. Tectonic setting and sources of magmatism related to the Southern Brazilian Shear Belt. Revista Brasileira de Geociências, 30(1): 186-189.

Bitencourt, M.F. \& Nardi, L.V.S. 2004. The role of xenoliths and flow segregation in the genesis and evolution of the Paleoproterozoic Itapema Granite, a crustally derived magma 
of shoshonitic affinity from southern Brazil. Lithos, 73(1-2): 1-19.

Brown, M. 2007. Crustal melting and melt extraction, ascentandemplacementinorogens: mechanisms and consequences. Journal of the Geological Society, 164(4): 709-730.

Büttner, S.H. 1999. The geometric evolution of structures in granite during continous deformation from magmatic to solidstate conditions: an example from the Central European Bariscan Belt. American Mineralogist, 84(11-12): 1781-1792.

Campos, R.S. \& Philipp, R.P. 2007. Petrografia e Geoquímica das Rochas Metavulcânicas Máficas e Ultramáficas da Região da Serra da Miséria. Revista Brasileira de Geociências, 3: 63-75.

Chemale Jr., F., Hartmann, L.A. \& Silva, L.D. 1995. Stratigraphy and tectonism of the Brasiliano Cycle in southern Brazil. Communications of the Geological Survey of Namibia, 10: 151166.

Chemale Jr., F., Mallmann, G., Bitencourt, M.F. \& Kawashita, K. 2012. Time constraints on magmatism along the Major Gercino Shear Zone, southern Brazil: implications for West Gondwana reconstruction. Gondwana Research, 22(1): 184-199.

Citroni, S.B., Basei, M.A.S., Siga Jr., O. \& Neto, J.M.R. 2001. Volcanism and stratigraphy of the Neoproterozoic Campo Alegre Basin, SC, Brazil. Anais da Academia Brasileira de Ciências, 73(4): 581-597.

De Toni, G.B., Bitencourt, M.F., Nardi, L.V.S., Florisbal, L.M., Almeida, B.S. \& Geraldes, M. 2020a. Dom Feliciano Belt orogenic cycle tracked by its pre-collisional magmatism: the Tonian (ca. 800 Ma) Porto Belo Complex and its correlations in southern Brazil and Uruguay. Precambrian Research, 342, 105702.

De Toni, G.B., Bitencourt, M.F., Konopásek, J., Martini, A., Andrade, P.H.S., Florisbal, L.M. \& Campos, R.S. 2020b. Transpressive strain partitioning between the Major Gercino Shear Zone and the Tijucas Fold Belt, Dom Feliciano Belt, Santa Catarina, southern Brazil. Journal of Structural Geology, 136, 104058.Dittmar, D., Meyer, W., Oncken, O., Schievenbusch, T., Walter, R. \& Von Winterfeld, C. 1994. Strain partitioning across a fold and thrust belt: the Rhenish Massif, Mid-European Variscides. Journal of Structural Geology, 16(10): 1335-1352.

Erdmann, S., Scaillet, B. \& Kellett, D.A. 2012. Textures of peritectic crystals as guides to reactive minerals in magmatic systems: new insights from melting experiments. Journal of Petrology, 53(11): 2231-2258.

Evans, M.A. \& Dunne, W.M. 1991. Strain factorization and partitioning in the North Mountain thrust sheet, central Appalachians, USA. Journal of Structural Geology, 13(1): 2135.

Florisbal, L.M., Janasi, V.A., Bitencourt, M.F. \& Heaman, L.M. 2012a. Space-time relation of post-collisional granitic magmatism in Santa Catarina, southern Brazil: U-Pb LA-MC-ICPMS zircon geochronology of coeval maficfelsic magmatism related to the Major Gercino Shear Zone. Precambrian Research, 216: 132151.

Florisbal, L.M., Bitencourt, M.F., Janasi, V.A., Nardi, L.V.S. \& Heaman, L.M. 2012b. Petrogenesis of syntectonic granites emplaced at the transition from thrusting to transcurrent tectonics in post-collisional setting: Wholerock and $\mathrm{Sr}-\mathrm{Nd}-\mathrm{Pb}$ isotope geochemistry in the Neoproterozoic Quatro Ilhas and Mariscal Granites, Southern Brazil. Lithos, 153: 53-71.

Guadagnin, F., Chemale Jr, F., Dussin, I.A., Jelinek, A.R., Santos, M.N., Borba, M.L. \& Alessandretti, L. 2010. Depositional age and provenance of the Itajaí Basin, Santa Catarina State, Brazil: implications for SW Gondwana correlation. Precambrian Research, 180(3-4): 156-182.

Hartmann, L.A., Bitencourt, M.F., Santos, J.O., McNaughton, N.J., Rivera, C.B. \& Betiollo, L. 2003. Prolonged Paleoproterozoic magmatic participation in the Neoproterozoic Dom Feliciano belt, Santa Catarina, Brazil, based on zircon U-Pb SHRIMP geochronology. Journal of South American Earth Sciences, 16(6): 477492.

Hartmann, L.A., Santos, J.O., McNaughton, N., Vasconcellos, M.A. \& Silva, L.C. 2000. Ion microprobe (SHRIMP) dates complex granulite from Santa Catarina, southern Brazil. Anais da Academia Brasileira de Ciências, 72(4), 559572. 
Hartmann, L.A., Silva, L.D. \& Orlandi Filho, V. 1979. O Complexo Granulítico de Santa Catarina; descrição e implicações genéticas. Acta Geológica Leopoldensia, 3(6): 93-112.

Jones, R.R. \& Tanner, P.G. 1995. Strain partitioning in transpression zones. Journal of Structural Geology, 17(6): 793-802.

Kruhl, J.H. 1996. Prism and basal plane parallel subgrain boundaries in quartz: A microstructural geothermobarometer. Journal of Metamorphic Geology, 14(5): 581-589.

Le Maitre, R.W. 2002. A Classification of Igneous Rocks and Glossary of Terms. Cambridge University Press, Cambridge, England, 193p.

Leite, J.A.D., Hartmann, L.A., Fernandes, L.A.D., McNaughton, N.J., Soliani Jr, E., Koester, E. \& Vasconcellos, M.A.Z. 2000. Zircon U$\mathrm{Pb}$ SHRIMP dating of gneissic basement of the Dom Feliciano Belt, southernmost Brazil. Journal of South American Earth Sciences, 13(8): 739-750.

Lenz, C., Fernandes, L.A.D., McNaughton, N.J., Porcher, C.C. \& Masquelin, H. 2011. U-Pb SHRIMP ages for the Cerro Bori Orthogneisses, Dom Feliciano Belt in Uruguay: evidences of a 800 Ma magmatic and 650 Ma metamorphic event. Precambrian Research, 185(3-4): 149163.

Lenz, C., Porcher, C.C., Fernandes, L.A.D., Masquelin, H., Koester, E. \& Conceição, R.V. 2013. Geochemistry of the Neoproterozoic (800-767 Ma) Cerro Bori orthogneisses, Dom Feliciano Belt in Uruguay: tectonic evolution of an ancient continental arc. Mineralogy and Petrology, 107(5): 785-806.

Masquelin, H., Fernandes, L.A.D., Lenz, C., Porcher, C.C. \& McNaughton, N.J. 2012. The Cerro Olivo Complex: a pre-collisional Neoproterozoic magmatic arc in Eastern Uruguay. International Geology Review, 54(10): 1161-1183.

Martil, M.M.D., 2016. O magmatismo de Arco Continental Pré-Colisional (790 Ma) e a reconstituição espaço-temporal do regime transpressivo (650 Ma) no Complexo Várzea do Capivarita, Sul da Província Mantiqueira. Porto Alegre, 168p, Tese de Doutorado, Programa de Pós-graduação em Geociências, Instituto de Geociências, Universidade Federal do Rio Grande do Sul.
Martil, M.M.D., Bitencourt, M.F., Nardi, L.V.S., Koester, E. \& Pimentel, M.M. 2017. Precollisional, Tonian (ca. $790 \mathrm{Ma}$ ) continental arc magmatism in southern Mantiqueira Province, Brazil: geochemical and isotopic constraints from the Várzea do Capivarita Complex. Lithos, 274: 39-52.

Martini, A., Bitencourt, M. F., Weinberg, R.F., De Toni, G.B. \& Nardi, L.V.S. 2019a. From migmatite to magma-crustal melting and generation of granite in the Camboriú Complex, south Brazil. Lithos, 340: 270-286.

Martini, A., Bitencourt, M.F., Weinberg, R.F. \& De Toni, G.B. 2019b. Melt-collecting structures and the formation of extraction dykes during syntectonic anatexis of the Camboriú Complex, south Brazil. Journal of Structural Geology, 127, 103866.

Passarelli, C.R., Basei, M.A.S., Siga, O. \& Harara, O.M.M. 2018. The Luis Alves and Curitiba Terranes: Continental Fragments in the Adamastor Ocean. In: Siegesmund, S., Basei, M.A., Oyhantçabal, P., \& Oriolo, S. (Eds.). Geology of Southwest Gondwana. Cham, Springer, p. 189-215.

Passchier, C.W.\&Trouw, R.A. 2005. Microtectonics. Berlin, Springer-Verlag, 2nd edition, 366p.

Peruchi, F.M. 2019. Geologia estrutural, petrografia, geoquímica e geocronologia $\mathrm{U}-\mathrm{Pb}$ do magmatismo granítico shoshonítico neoproterozóico pós-colisional sintectônico da zona de cisalhamento Major Gercino, região de Porto Belo, SC. Porto Alegre, 97p. Dissertação de Mestrado, Programa de Pósgraduação em Geociências, Instituto de Geociências, Universidade Federal do Rio Grande do Sul.

Philipp, R.P., Mallmann, G., Bitencourt, M.F., Souza, E.R., Souza, M.M.A., Liz, J.D., Wild, F., Arendt, S., Oliveira, A.S., Duarte, L., Rivera, C.B. \& Prado, M. 2004. Caracterização Litológica e Evolução Metamórfica da Porção Leste do Complexo Metamórfico Brusque, Santa Catarina. Revista Brasileira de Geociências 34: 21-34.

Sawyer, E.W. 2008. Atlas of migmatites. The Canadian Mineralogist, Special Publication 9. N RC Research Press, Ottawa, Ontario, Canada, $371 \mathrm{p}$.

Sawyer, E.W. 2010. Migmatites formed by water- 
fluxed partial melting of a leucogranodiorite protolith: Microstructures in the residual rocks and source of the fluid. Lithos, 116(3-4): 273286.

Silva, L.C. 1991. O Cinturão Metavulcanossedimentar Brusque e a evolução policíclica das faixas dobradas Proterozóicas no sul do Brasil: uma revisão. Revista Brasileira de Geociências, 21(1): 6073.

Silva, L.C., Hartmann, L.A., McNaughton, N.J. \& Fletcher, I. 2000. Zircon U-Pb SHRIMP dating of a Neoproterozoic overprint in Paleoproterozoic granitic-gneissic terranes, southern Brazil. American Mineralogist, 85: 649-667.

Silva, L.C., McNaughton, N.J. \& Fletcher, I.R. 2005. SHRIMP U-Pb zircon geochronology of Neoproterozoic crustal granitoids (Southern Brazil): a case for discrimination of emplacement and inherited ages. Lithos, 82(34): 503-525.

Silva, A.O.M., Porcher, C.C., Fernandes, L.A.D. \& Droop, G. 2008. Termobarometria da Suíte Metamórfica Várzea do Capivarita (RS): embasamento do Cinturão Dom Feliciano. Brazilian Journal of Geology, 32(4): 419-432.

Stipp, M., Stünitz, H., Heilbronner, R. \& Schmid, S.M. 2002a. The eastern Tonale fault zone: a 'natural laboratory' for crystal plastic deformation of quartz over a temperature range from 250 to $700 \mathrm{C}$. Journal of Structural Geology, 24(12): 1861-1884.

Stipp, M., Stünitz, H., Heilbronner, R. \& Schmid, S.M. 2002b. Dynamic recrystallization of quartz: correlation between natural and experimental conditions. In: De Meer, S., Drury, M.R, De Bresser, J.H.P. \& Pennock, G.M. (Eds). Deformation Mechanisms, Rheology and Tectonics: Current Status and Future Perspectives. Geological Society, London, Special Publications 200, p. 171 - 190.
Van der Pluijm, B.A. \& Marshak, S. 2004. Convergence and Collision In: Van der Pluijm, B.A. \& Marshak S. (2nd Ed). Earth Structure: An Introduction to Structural Geology and Tectonics. New York/London, W.W. Norton \& Company, 412-443.

Vernon,R.H.2011. Microstructuresofmelt-bearing regional metamorphic rocks. Geological Society of America Memoirs, 207: 1-11.

Weinberg, R.F. \& Hasalová, P. 2015. Waterfluxed melting of the continental crust: A review. Lithos, 212: 158-188.

Whitney, D.L. \& Evans, B.W. 2010. Abbreviations for names of rock-forming minerals. American Mineralogist, 95(1): 185-187. 